\title{
China, Precios de Commodities y Desempeño de América Latina: Algunos Hechos Estilizados*
}

\author{
PATRICIO JARAMillo \\ Superintendencia de Bancos e Instituciones Financieras \\ SERGIO LEHMANN \\ Banco Central de Chile \\ DAVID MORENO \\ Banco Central de Chile
}

The Chinese economy has become one of the most important consumers of a broad range of commodities. This work aims at measuring the impact of China's expansion on commodity prices and illustrate its effect on Latin American economies. It is found a positive and significant relation between China's industrial production and the evolution of prices of metals, fuels, and to a lesser extent, grains and other farm commodities. In general, Latin American economic cycles are positively correlated with commodity prices and China's economic activity.

JEL: C2, F0, G0

Keywords: China, Precios de Commodities, América Latina, Modelo de Corrección de Errores

\section{INTRODUCCIÓN}

En los últimos veinte años China ha pasado de ser una economía principalmente agrícola y muy poco integrada al resto del mundo, a ser un actor central en el desarrollo económico global. Hoy representa en torno a un $12 \%$ del producto

\footnotetext{
* Este trabajo fue preparado cuando todos sus autores pertenecían al Banco Central de Chile y fue presentando en el seminario "Los efectos de China en América Latina" organizado por el Banco Central de Chile. Se agradecen los comentarios de Roberto Álvarez, Rodrigo Fuentes, Rodrigo Valdés y Alejandro Fernández, y a Jorge Restrepo por facilitarnos algunos de los programas utilizados. También agradecemos los comentarios de los asistentes al Seminario de Macroeconomía y Finanzas del Banco Central de Chile y de dos árbitros anónimos. Las opiniones, errores u omisiones son de responsabilidad exclusiva de sus autores y no comprometen la visión del Banco Central de Chile.

Email: slehmann@bcentral.cl,dmoreno@bcentral.cly pjaramillo@bcentral.cl.
} 
mundial medido a paridad de poder de compra (5\% en dólares corrientes), el origen de cerca del $15 \%$ del comercio mundial de manufacturas y el principal consumidor de productos básicos.

El impacto de China en el escenario económico mundial despierta especial atención, no sólo por su sobresaliente crecimiento, en torno a 10\% durante los últimos años, sino también por su enorme tamaño. En la actualidad es la cuarta economía del mundo -medido a paridad de poder de compra-y aportó el $25 \%$ del crecimiento mundial de 2006. Su apertura al comercio internacional ha generado oportunidades para el resto del mundo, aunque también ha puesto mayor exigencia en términos de competitividad sobre economías emergentes que se especializan en bienes manufacturados intensivos en el uso de mano de obra no calificada, como son los casos de Brasil, México, India y otras economías del sudeste asiático. Esto ha motivado la aparición de un número importante de estudios abocados a evaluar los efectos de China sobre la economía mundial.

Dado el significativo incremento que China habría generado en la demanda de productos básicos, lo que es de particular interés para América Latina, es posible distinguir en la región, a lo menos, dos tipos de países: aquellos en los que una fracción importante de sus exportaciones corresponde a manufacturas y, por tanto, han pasado a ser competidores de China en ese ámbito, como es el caso de México especialmente y de Brasil, y aquellos que exportan principalmente commodities y que, por lo tanto, han visto incrementada significativamente su demanda externa.

Lo anterior podría sugerir que los primeros se han visto menos beneficiados, al menos directamente, por el desarrollo que ha mostrado China en los últimos años, lo que se ha reflejado en un crecimiento económico menos dinámico, como se estudia en la Sección 4. Los países exportadores de productos básicos, en tanto, han registrado un significativo crecimiento de sus exportaciones, lo que ha impactado positivamente sobre su desempeño económico.

Si bien en la literatura se encuentran algunos estudios por regiones, éstos se concentran principalmente en los efectos sobre el comercio de Asia. En esa línea, Yang (2003) indica que Asia Emergente compite con China tanto en el comercio exterior como por la inversión extranjera directa, lo que hace que en el agregado salga perjudicada en alrededor de $-0,2 \%$ del PIB, lo que de todas formas hablaría de un efecto relativamente pequeño.

Para el caso de América Latina, la evidencia que se encuentra es aún menor. García et al. (2007) presentan hechos estilizados y muestran los efectos para la región en general y no de forma individual. Por otra parte, Mesquita (2004) utilizando datos de comercio para una muestra de países latinoamericanos, encuentra un pequeño impacto negativo en el sector manufacturero, pero que constituiría una tendencia que se prolongaría en el tiempo. Además, indica que el auge manufacturero chino estaría basado en una ilimitada dotación de mano de obra, veloz crecimiento de la productividad, economías de escala y una importante intervención estatal, lo que estaría detrás del éxito exportador. Blázquez-Lidoy et al. (2006) indican que México, en ese sentido, es la economía más amenazada, pues tiene la estructura de comercio más parecida a China entre los países de Latinoamérica. 
En línea con las investigaciones anteriores, Álvarez y Claro (2006) establecen que para el caso de Chile, si bien los precios de las manufacturas chinas explican en parte la penetración de éstas, es más bien la variedad y la creciente calidad de su producción lo que explica este fenómeno ${ }^{1}$. En síntesis, de acuerdo a la literatura empírica, las industrias más vulnerables a la competencia china serían aquellas basadas en la utilización de mano de obra no calificada y constituirían el sector más afectado por la apertura comercial y desempeño económico de este país. No obstante, este menor desempeño debería verse compensado en el caso de América Latina por una mejora del sector servicios y recursos naturales, especialmente en este último, donde la región presenta cierta especialización ${ }^{2}$.

FMI (2004) estudia 10 regiones y siete sectores productivos, donde América Latina está dividida en dos bloques: exportadores de petróleo (México, Colombia y Venezuela) y "el resto" (países en vías de desarrollo del hemisferio occidental). En el caso del primer grupo, los envíos al exterior como resultado de la demanda de bienes importados aumentarían en algo menos de 3\%, mientras que el efecto total sobre la economía se encuentra una mayor expansión del producto que se sitúa entre una y dos décimas. En el resto de las economías, en tanto, las exportaciones e importaciones se reducirían en torno a $1 \%$. Los sectores más beneficiados en ambos grupos serían la agricultura, minería y, en menor proporción, el sector servicios. En tanto, el sector manufacturero, textiles y prendas de vestir serían los más perjudicados ${ }^{3}$. Blázquez-Lidoy et al. (2006), a través de un análisis de similitud de exportaciones y de especialización en la producción (índice de Balassa) ratifica que la competencia en manufactura es especialmente alta para México. Sin embargo, este país enfrenta oportunidades importantes en el comercio intraindustria. Además, podría aprovechar los menores costos de transporte y coordinación que le otorga su cercanía a Estados Unidos. Esto es válido también para el caso de transportes y maquinaria en Brasil y productos químicos en Colombia. Sin embargo, esta situación dejaría a las economías con mayor exposición a shocks de términos de intercambio, lo que plantea otros riesgos a considerar para las economías latinoamericanas.

\footnotetext{
${ }^{1}$ Schott (2006), utilizando datos de importaciones de Estados Unidos por productos, hace una comparación de los productos de origen chino con aquellos de los países de la OCDE. Los primeros reciben un precio menor que los segundos, lo que es lógico dado el menor costo de la mano de obra relativo de China; sin embargo, la cantidad exportada a Estados Unidos por China es mayor que la de los países de la OCDE, inclusive en categorías no intensivas en mano de obra no calificada, como los artículos eletrónicos, lo que indica que existe un factor de "calidad" no siempre presente en estimaciones tradicionales.

2 Para mayor detalle, véase el Anexo A2, que presenta una tabla de especialización de los distintos países de América Latina. De ella se desprende una fuerte especialización de la mayoría de las economías en bienes asociados a recursos naturales. Los casos de Brasil y México son algo distintos, considerando un rol importante de las manufacturas, especialmente en relación a equipos de transporte.

${ }^{3}$ La separación de los países exportadores de petróleo del resto de la muestra de América Latina merece algunos reparos. Los efectos negativos en volumen de comercio podrían deberse al mayor impacto en el sector manufacturero, textiles y vestuario de México y Colombia, que no serían compensados por los combustibles.
} 
Por otra parte, en la revisión de literatura sobre fallacy of composition de Mayer (2003), se cita el trabajo de Yang y Vines (2000) que, mediante análisis contrafactuales, llega a la conclusión que esta mayor competencia aportada por China es contrapesada por el efecto de demanda complementaria, que es mayor mientras mayor es el comercio con China y el grado de complementariedad de sus estructuras productivas. A su vez, en el largo plazo, esto estimularía el aumento de productividad en el sector transable del resto de las economías, aumentando de esta manera su competitividad.

Así, la contribución de este trabajo es presentar una evaluación y cuantificación del efecto del crecimiento de China en los precios de productos básicos, con especial énfasis en aquellos donde América Latina tiene mayor participación. Además, se muestran algunos hechos estilizados, a través de correlaciones dinámicas simples, que sugieren preliminarmente el vínculo de éstos precios con el desempeño económico de la región. Entre los trabajos que tratan acerca de precios de commodities y China, destaca US Trade Commission (2006), que hace una revisión completa sobre los distintos intentos de estimar el efecto de China en el precio del petróleo, aluminio, productos forestales y residuos ferrosos, además de hacer una descripción de la estructura de comercio en estos bienes. El autor sugiere que para el caso del cobre -en el corto plazo-, incrementos o desplazamientos de la demanda de China causarían grandes cambios en los precios internacionales debido a la lentitud del ajuste de la oferta. A largo plazo, el aumento de la demanda de China aún produciría incrementos en los precios. Esto está en contraposición con estudios anteriores donde un aumento de la demanda de China por petróleo y aluminio (medido como el aumento del consumo de China), originaría un incremento de los precios de $12 \%$ a $37 \%$ y de $8 \%$ a $52 \%$, respectivamente, durante el período comprendido entre los años 1995 y 2004 (Krichene, 2005; Watkins y McAleer, 2005, entre otros). Respecto al consumo a largo plazo de bienes básicos por parte de China, Kaplinsky (2006) compara esta economía con otras economías asiáticas que enfrentaron un proceso de desarrollo económico similar, indicando que esta mayor demanda seguiría creciendo en el tiempo, al mantenerse las altas tasas de crecimiento de la actividad, especialmente si se considera que el grado de actividad industrial en relación a su nivel de ingreso per cápita es muy alta en comparación con otras economías emergentes.

El presente trabajo se ha organizado en cuatro secciones adicionales. En la Sección 2 se muestran algunos antecedentes descriptivos sobre el desarrollo económico de China durante los últimos 20 años. En la Sección 3 se presenta una forma reducida de modelar el efecto de China sobre el precio de commodities, incluyendo algunas agrupaciones de estos como metales, combustibles y productos agrícolas. En la Sección 4 se presentan algunos hechos estilizados respecto a la actividad de China y el desempeño de los principales países de América Latina. Finalmente, en la Sección 5 se presentan las principales conclusiones. 


\section{Evolución de la Economía China}

En los últimos 20 años, la economía mundial ha visto la aparición de China como un actor cada vez más relevante. Tras una larga época de aislamiento, en los ochenta China modifica sus políticas e inicia su inserción en la economía mundial, al ir reduciendo gradualmente sus barreras al comercio internacional. Ello le ha permitido multiplicar por siete su intercambio comercial con el resto del mundo.

Las exportaciones chinas han pasado a concentrarse principalmente en manufacturas y productos electrónicos, que hoy en día representan cerca del $90 \%$ del total. Creciente importancia han ido adquiriendo los productos asociados a maquinaria pesada y de transporte. En cuanto a las importaciones, éstas han ido aumentando sostenidamente, destacando la participación de las materias primas, incluyendo combustibles y productos agropecuarios, como se puede apreciar en los Gráficos 1 y 2 .

\section{GRÁFICO 1 \\ EXPORTACIONES DE CHINA POR CATEGORÍAS \\ (Miles de millones de dólares)}

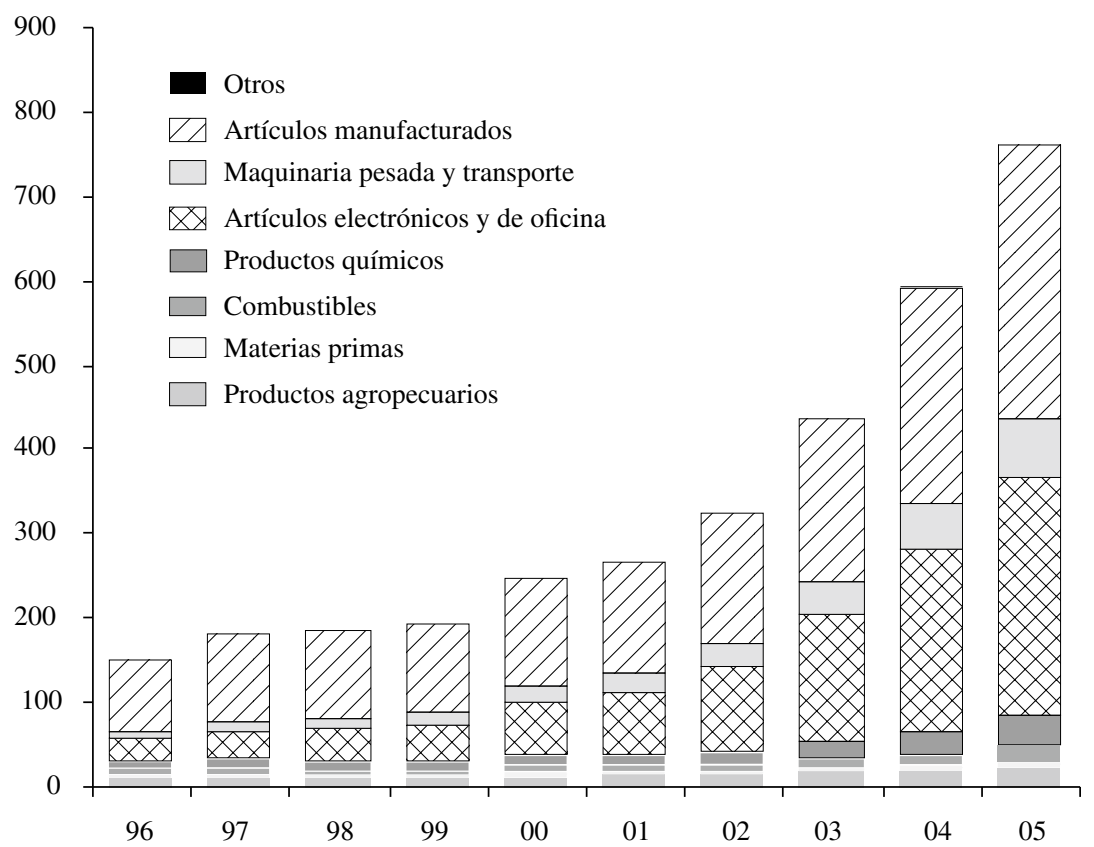

Fuente: UNCTAD. 


\section{GRÁFICO 2 \\ IMPORTACIONES DE CHINA POR CATEGORÍA \\ (Miles de millones de dólares)}

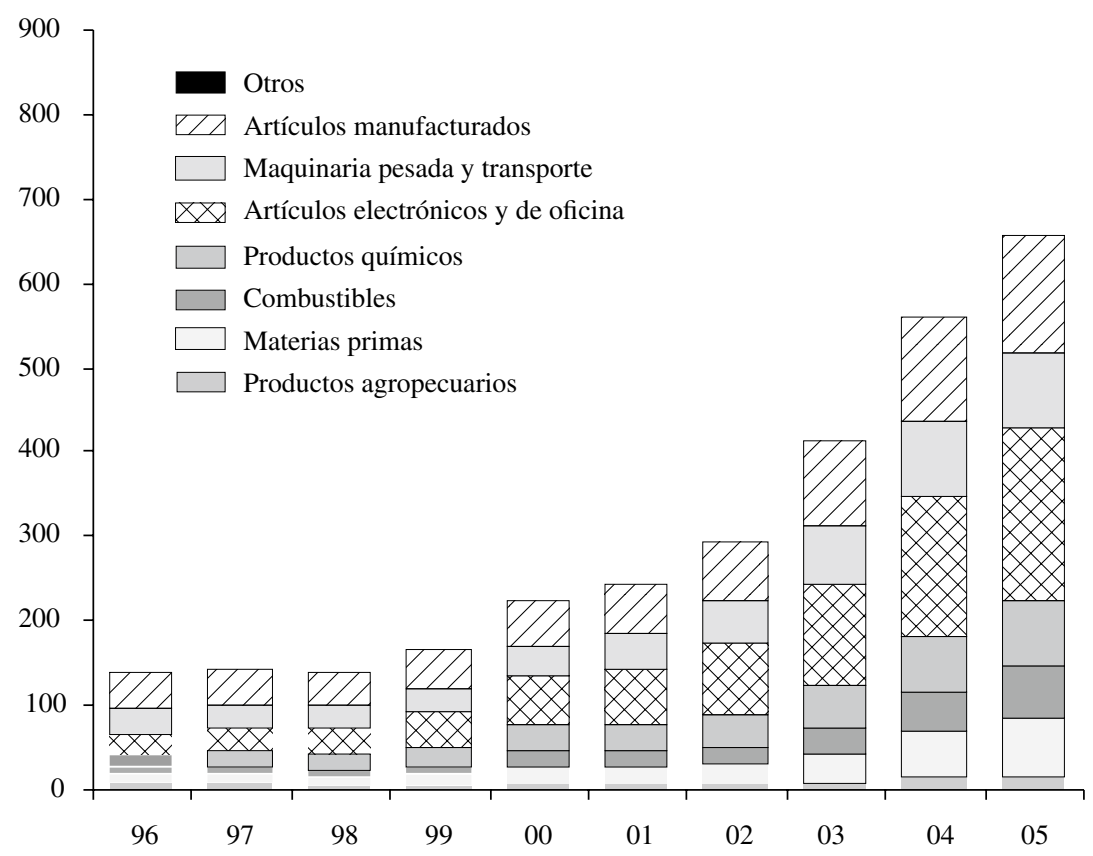

Fuente: UNCTAD.

Este hecho ha llevado a China a convertirse en el tercer actor más importante en términos de participación en el comercio internacional, sólo detrás de Estados Unidos y Alemania. El Gráfico 3 muestra que China hoy día representa alrededor de $7 \%$ del comercio mundial de bienes.

Este dinamismo ha llevado a dicha economía a crecer sostenidamente durante los últimos veinte años por sobre el resto de las economías del mundo, convirtiendo a esta economía en un actor cada vez más importante para explicar el crecimiento mundial (Veáse Gráfico 5). Tal como se aprecia en el Gráfico 4, casi el $25 \%$ del crecimiento mundial registrado en 2005 es directamente atribuible a la expansión de China.

El mundo se ha visto beneficiado del extraordinario dinamismo que ha mostrado China durante los últimos años, asociado a su proceso de apertura comercial y elevado crecimiento económico. Estos beneficios podrían manifestarse a través de a lo menos tres mecanismos básicos: (1) mayor competencia en el sector manufacturero, (2) inversión extranjera directa y (3) por mayor demanda por productos básicos. 
GRÁFICO 3

PARTICIPACIÓN DE CHINA EN EL COMERCIO MUNDIAL

(Porcentaje)

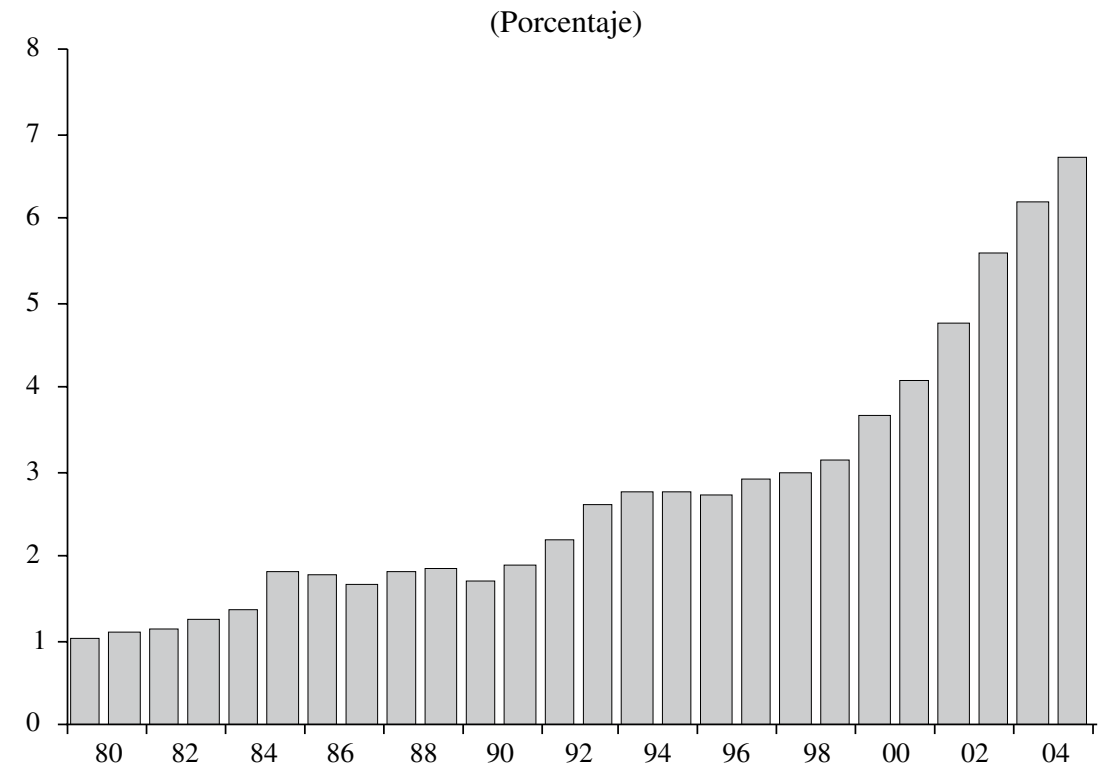

Fuente: FMI.
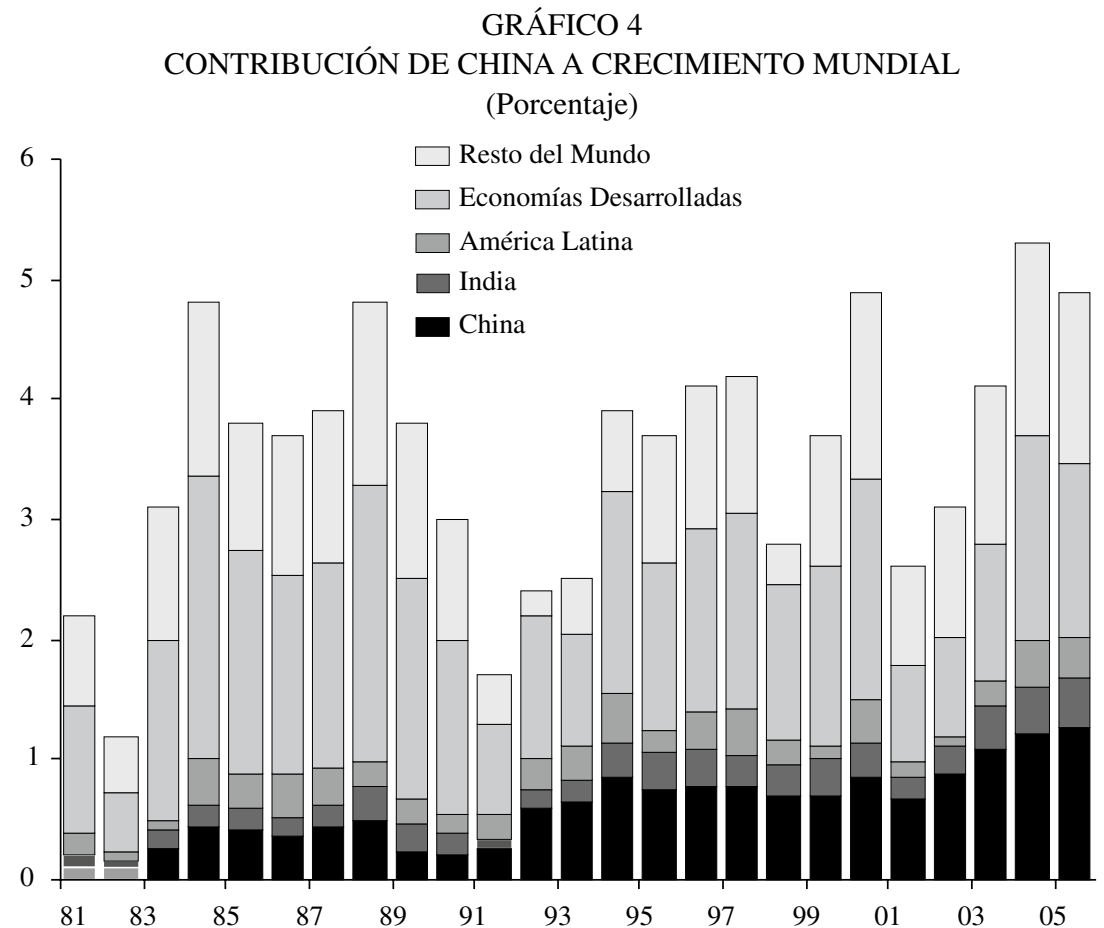

Fuente: Elaboración propia a partir de WEO de septiembre de 2006. 


\section{GRÁFICO 5 \\ CRECIMIENTO REAL DEL PIB \\ (Variación anual, porcentaje)}

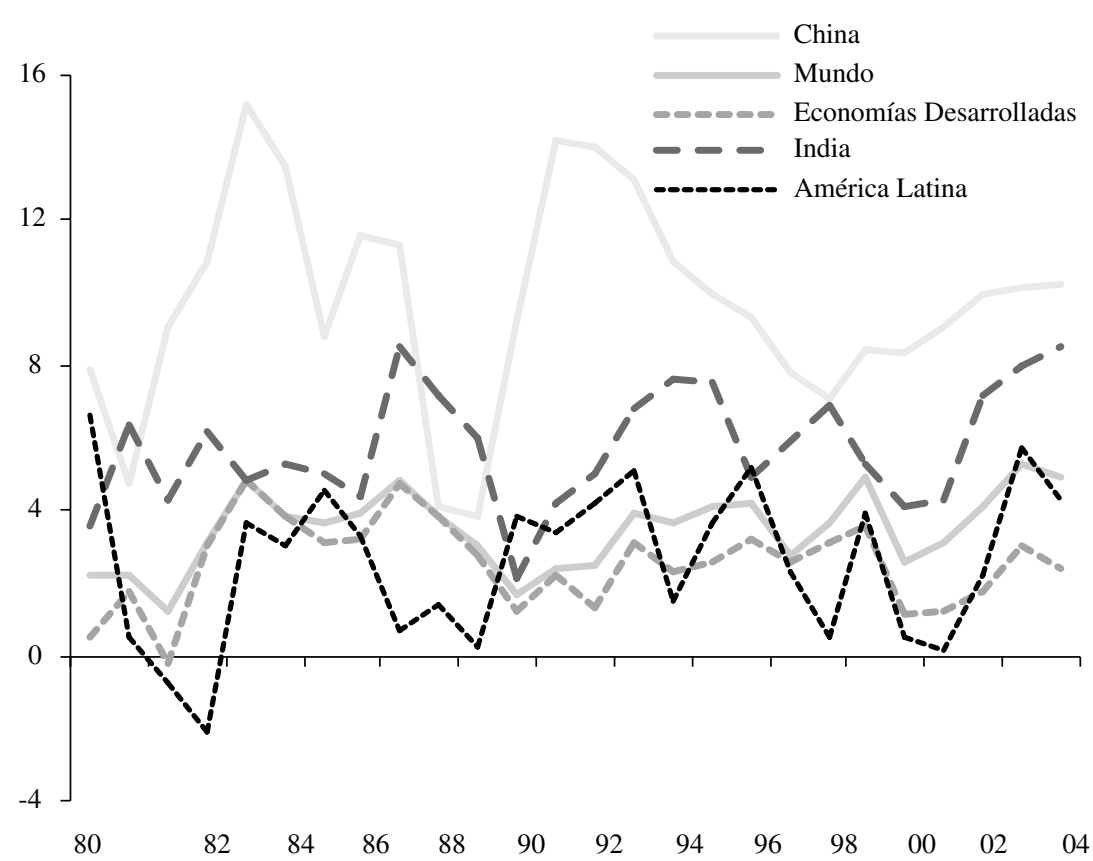

Fuente: WEO, septiembre de 2006.

Algunos estudios se focalizan en la cuantificación de los efectos en comercio, bienestar y asignación de factores y producción, mediante modelos de equilibrio general. En este espíritu, el GTAP (de su sigla en inglés del Proyecto de Análisis del Comercio Global de la Universidad de Purdue), se enfoca en los efectos en términos de intercambio y flujo de comercio. A partir de él se concluye que el ingreso de China a la Organización Mundial de Comercio en 2001 ha beneficiado a la economía mundial no sólo por sus exportaciones de bajo costo, sino también por el enorme potencial de demanda que representa, y que los beneficios que reciba cada país o región en particular dependerá de la forma en que compitan con los bienes producidos en China ${ }^{4}$.

${ }^{4}$ Entre estos estudios están Ianchovichina y Martin (2006) y FMI (2004). 


\section{China en el Boom de Precio de Commodities}

El desarrollo económico de China de los últimos años, ha llevado a esta economía a convertirse en uno de los principales consumidores de productos básicos. En efecto, tal como se muestra en el Cuadro 1, hacia el año 2005, China se convierte en el mayor consumidor de cobre, mientras en petróleo muestra un crecimiento promedio anual de su demanda en torno a $8 \%$, lo que la ubica sólo detrás de Estados Unidos en términos de consumo. Si bien China consume menos petróleo que la Zona Euro, prácticamente duplica el consumo que registra Alemania por sí sola.

En el caso de productos agrícolas, como la soja, también se ubica en el primer lugar, acumulando un crecimiento promedio anual de casi $13 \%$ durante los últimos 5 años. En el mercado del maíz cuyo precio ha tendido a aumentar fuertemente en los últimos años, China es el segundo mayor consumidor detrás de Estados Unidos.

La alta demanda por productos básicos de China seguiría presente, si se toma en consideración que su consumo y nivel de producción industrial es muy alto en comparación con otras economías que tienen, o tuvieron, un ingreso per cápita similar (FMI, 2004). En el Cuadro 2 se compara China con Japón y Corea del Sur en cuanto a su trayectoria de consumo. Se puede apreciar que las economías mencionadas aumentan fuertemente su consumo al aumentar su nivel de ingreso, lo que es esperable para el caso de China, y en especial dada su alta participación de la industria manufacturera en la producción del país.

Con el fin de modelar el efecto de China en los precios internacionales de productos básicos, se procedió a utilizar un enfoque tradicional considerando variables macroeconómicas básicas, además de la producción industrial de China. Esto, considerando los efectos globales que direccionan los precios, además de factores propios de cada industria (Borensztein y Reinhart, 1994). Asimismo, Dornbusch (1985), Morrison y Chu (1984) y Gilbert (1989) plantean modelos de equilibrio parcial usando como determinantes la producción industrial y el tipo de cambio real. Para capturar la evolución de cada uno de los mercados por separado se incluye la variable inventarios, cuando se dispone de tal información.

En esta Sección se usaron datos para más de cuarenta series de precios de commodities, entre los que se cuentan cobre, petróleo, gasolina, cereales, maíz, aluminio, níquel, algodón, plata, oro, azúcar, trigo, soja, etcétera, además de índices generales de precios (Fuente: Merrill Lynch y Reuters) e índices específicos para precios de metales, de energía, de metales preciosos, de soft commodities (granos principalmente), de ganadería y de bienes agrícolas. Asimismo, se usó como deflactor el índice de precios al productor de Estados Unidos y la variable inventarios en bolsa, en los casos relevantes, para capturar el mayor o menor grado de estrechez de oferta en los distintos mercados. Todas las series utilizadas fueron extraídas de Bloomberg, en frecuencia mensual desde enero de 1970 a diciembre de 2006, aunque la mayoría de las estimaciones consideraron una muestra más restringida dada la disponibilidad de datos para la producción industrial de China, que se encuentra disponible sólo desde 1992. La serie de tipo de cambio real 


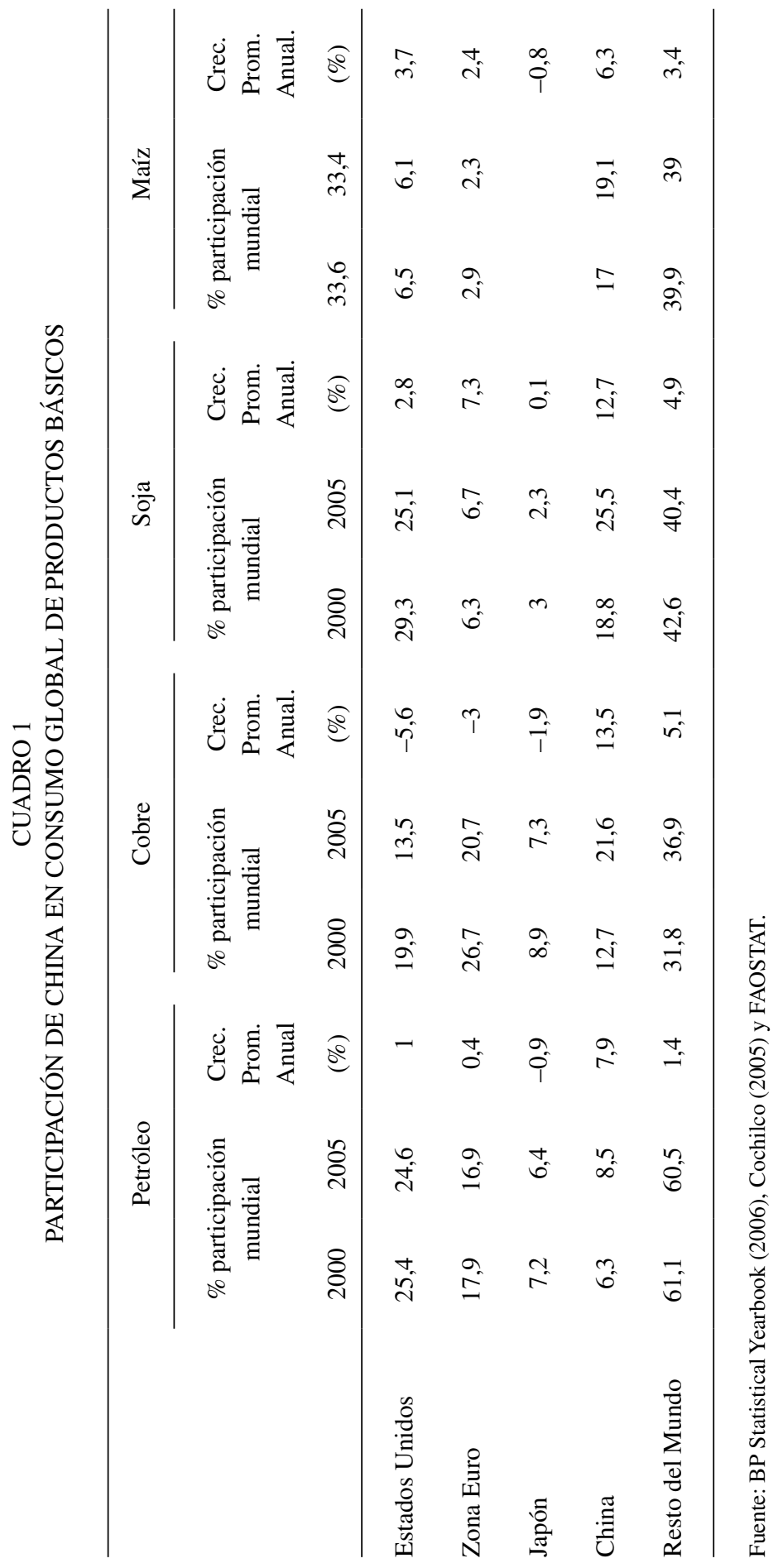


multilateral corresponde a la reportada por la Reserva Federal de Estados Unidos y que utiliza ponderadores de acuerdo a los principales socios comerciales de dicha economía 5 . Finalmente, se incluyó como variable de actividad la producción industrial de los países de la OCDE, que agrupa a los principales consumidores de productos básicos ${ }^{6}$.

CUADRO 2

CONSUMO DE ALGUNOS METALES DE CHINA, JAPÓN Y COREA DEL SUR EN RETROSPECTIVA

\begin{tabular}{|c|c|c|c|c|}
\hline & \multicolumn{3}{|c|}{ Kilos per cápita } & \multirow{2}{*}{$\begin{array}{c}\text { PIB per cápita } \\
\text { (dólares de } \\
\text { 1995) }\end{array}$} \\
\hline & Aluminio & Cobre & Acero & \\
\hline \multicolumn{5}{|l|}{ Japón } \\
\hline 1955 & 0,6 & 1,2 & 80 & 5.559 \\
\hline 1975 & 10,5 & 7,4 & 599 & 21.869 \\
\hline \multicolumn{5}{|c|}{ Corea del Sur } \\
\hline 1975 & 1,0 & 1,3 & 54 & 2.891 \\
\hline 1995 & 15,0 & 8,1 & 827 & 10.841 \\
\hline \multicolumn{5}{|l|}{ China } \\
\hline 1990 & 0,7 & 0,6 & 59 & 342 \\
\hline 1999 & 2,3 & 1,2 & 108 & 756 \\
\hline 2002 & 3,3 & 2,0 & 160 & 933 \\
\hline 2003 & 4,0 & 2,4 & 200 & 1.103 \\
\hline
\end{tabular}

Fuente: Kaplinsky (2006).

\subsection{Raíz Unitaria y Cointegración}

Primeramente se realizaron los contrastes usuales de raíz unitaria a las series de precios, actividad, nivel de inventarios y tipo de cambio, utilizando el test de Dickey Fuller con GLS, remoción de tendencia (DFGLS) y un criterio de información de Schwarz modificado para la elección de rezagos de Elliott et al. (1996), que corrigen en parte los problemas conocidos de bajo poder y distorsiones de tamaño de este tipo de contrastes. El test DFGLS propone una modificación del test de Dickey Fuller aumentado (ADF) tradicional, donde a los datos se les

\footnotetext{
5 Públicamente disponible en http://www.federalreserve.gov/releases/H10/Summary/

6 Australia, Austria, Bélgica, Canadá, Dinamarca, Finlandia, Francia, Alemania, Grecia, Islandia, Irlanda, Italia, Japón, Luxemburgo, México, Holanda, Nueva Zelanda, Noruega, Portugal, España, Suecia, Suiza, Turquía, Reino Unido y Estados Unidos.
} 
extrae una tendencia tal que las variables explicativas son removidas de los datos antes de correr la regresión. El contraste define una cuasidiferencia de la serie, que depende de los valores de $a$ que representan un punto específico para la hipótesis alternativa contra la cual se quiere contrastar la hipótesis nula de raíz unitaria. Así, tenemos formalmente una cuasidiferencia de la serie, definida como:

$$
d\left(y_{t} \mid a\right)= \begin{cases}y_{t} & \text { si } t=1 \\ y_{t}-a y_{t-1} & \text { si } t>1\end{cases}
$$

Luego, se considera una regresión por mínimos cuadrados ordinarios (MCO) para la serie cuasidiferenciada de la forma:

$$
d\left(y_{t} \mid a\right)=d\left(x_{t} \mid a\right)^{\prime} \delta(a)+\eta_{t}
$$

La variable $x_{t}$ contiene la constante, o la constante y la tendencia, y $\hat{\delta}(a)$ corresponde a los estimadores MCO de esta regresión. Para esto, es crítica la elección de $a$, donde Elliott et al. (1996) sugieren que $a=\tilde{a}$ de manera que:

$$
\tilde{a}=\left\{\begin{array}{lll}
1-7 / T & \text { si } & x_{t}=\{1\} \\
1-13.5 / T & \text { si } & x_{t}=\{1, t\}
\end{array}\right.
$$

En tanto, la serie GLS sin tendencia, $y_{t}^{d}$, se obtiene utilizando las estimaciones asociadas con $\tilde{a}$ :

$$
y_{t}^{d} \equiv y_{t}-x^{\prime}{ }_{t} \hat{\delta}(\tilde{a})
$$

Posteriormente, se procede a estimar un test ADF tradicional para la variable $y_{t}^{d}$ :

$$
\Delta y_{t}^{d}=\alpha y_{t-1}^{d}+\beta_{1} \Delta y_{t-1}^{d}+\ldots+\beta_{p} \Delta y_{t-p}^{d}+v_{t}
$$

En tanto, el criterio modificado de información de Schwarz agrega un término adicional $(\tau)$ al criterio tradicional:

$$
S M=-2\left(\frac{l}{T}\right)+(\kappa+\tau) \frac{\log (T)}{T}, \text { con } \tau=\frac{\alpha^{2}}{\sigma^{2}} \sum \tilde{y}_{t-1}^{2}
$$

En esta ecuación, $l$ es el logaritmo del valor de la función de verosimilitud de un modelo de $k$ parámetros y $T$ observaciones. El Cuadro 3 presenta los resultados de este test para las distintas series individuales e índices de precios. 


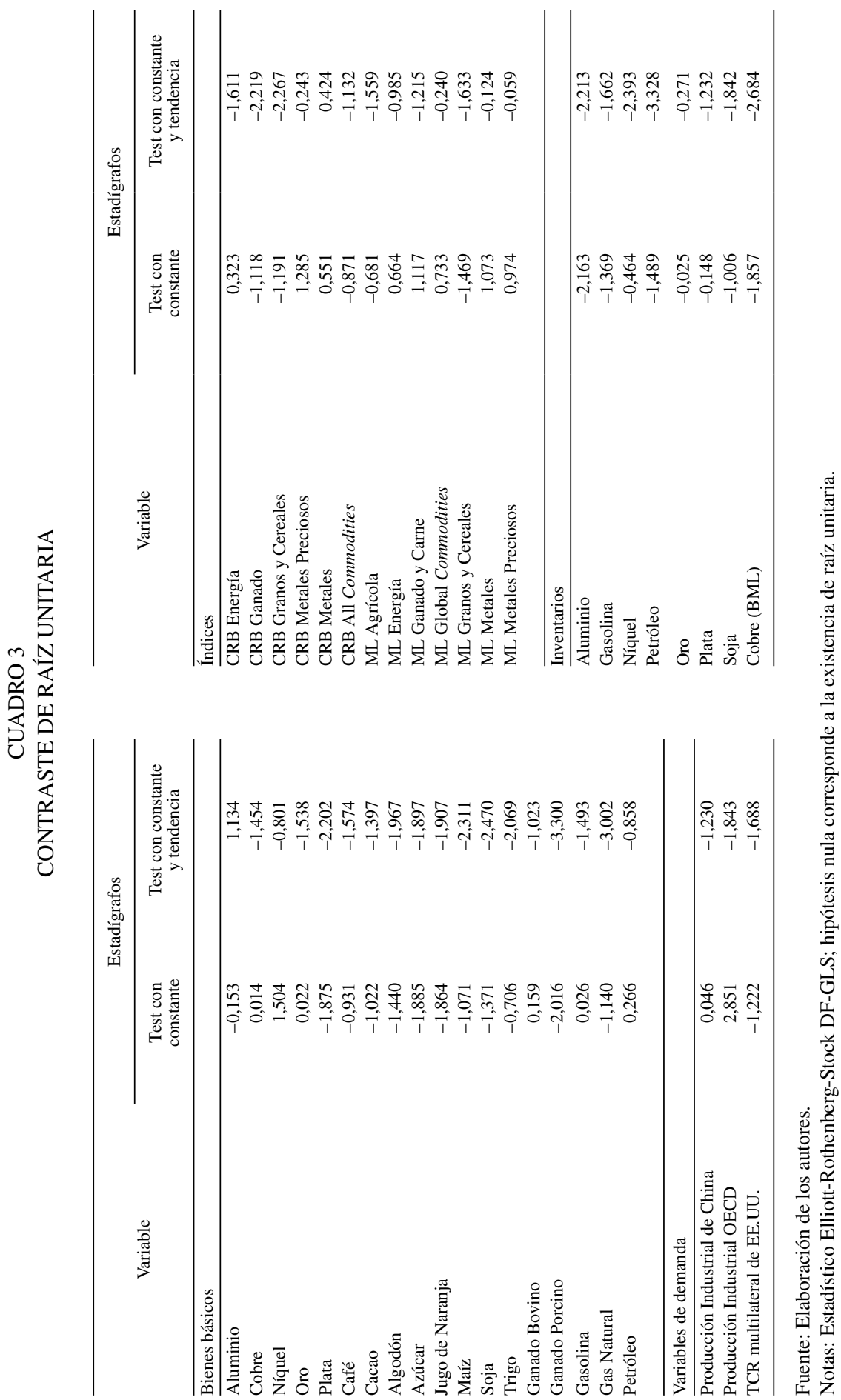


Se observa que no es posible rechazar la hipótesis nula de raíz unitaria en los casos analizados, lo que valida la estrategia de utilizar un enfoque de cointegración si es que existe, a lo menos, un vector de cointegración ${ }^{7}$.

Para ello, se procedió a realizar test de cointegración sugerido por Johansen. Este tipo de contraste permite determinar si un grupo de series no estacionarias cointegran entre sí. Así, una característica de las variables cointegradas es que su trayectoria temporal es influenciada por desviaciones respecto del equilibrio de largo plazo. El test es relativamente simple y se basa en un vector autorregresivo de orden $p$ (Johansen 1991, 1995):

$$
y_{t}=A_{1} y_{t-1}+\ldots .+A_{p} y_{t-p}+B x_{t}+\varepsilon_{t}
$$

Aquí, $y_{t}$ es un vector de variables no estacionarias $I(1), x_{t}$ un vector de variables determinísticas y $\varepsilon_{t}$, las innovaciones. Reescribiendo la expresión anterior, se obtiene:

$$
\Delta y_{t}=\Pi y_{t-1}+\sum_{i=1}^{p-1} \Gamma_{i} \Delta y_{t-i}+B x_{t}+\varepsilon_{t}
$$

donde,

$$
\Pi=\sum_{i=1}^{p} A_{i}-I
$$

$$
\Gamma_{i}=-\sum_{j=i+1}^{p} A_{j}
$$

El test estima la matriz $\Pi$ a partir de un VAR no restringido y testea si se pueden rechazar las restricciones implícitas para el rango de $\Pi$.

De acuerdo a los test de Johansen ${ }^{8}$, el rango de cointegración resultó ser 1 o 2 para la mayoría de los $\operatorname{casos}^{9}$. Por lo tanto, en la próxima sección se presenta un modelo de corrección de errores, dado que la dinámica de corto plazo de las variables del sistema estaría influenciada por las desviaciones del equilibrio.

\footnotetext{
${ }^{7}$ Este resultado es robusto al utilizar los test más estándares de raíz unitaria, con la limitante natural que tienen este tipo de contrastes para lidiar con la existencia de quiebres estructurales (Perrón, 1989). Para ello, se testeó adcionalmente la existencia de quiebres de manera endógena de acuerdo a Hansen (1997) y Bai y Perrón (1998). Si bien los resultados son muy dependientes a la especificación utilizada, en general mostraron existencia de quiebre más reciente para muchos de los commodities considerados entre el 2001 y 2003. Este hecho refuerza las conclusiones encontradas en este trabajo.

${ }^{8}$ Engle y Granger (1987) apuntan que una combinación lineal de dos o más series no estacionarias puede ser estacionaria. Si esta combinación lineal existe, se dice que las series son cointegradas. La combinación lineal se denomina ecuación de cointegración y debe ser entendida como la relación de largo plazo o de equilibrio entre las variables.

${ }^{9}$ Esto es robusto al cambiar la frencuencia de datos, tanto a nivel trimestral como anual.
} 


\subsection{Modelo de Corrección de Errores}

La estructura del modelo de corrección de errores permite distinguir entre el efecto en la dinámica de corto y de largo plazo que podría generar China en los distintos precios. Para asegurar que los estimadores de los parámetros de cointegración sean consistentes, la ecuación de largo plazo se estimó por el método DOLS (dynamic ordinary least squares; Stock y Watson, 1993), tal como se sugiere en Jaramillo y Selaive (2006) para el caso de la modelación del precio del cobre. Así, el modelo para la ecuación de cointegración queda definido como:

$$
\begin{aligned}
p_{t}= & \alpha+\beta_{0} \text { trend }+\beta_{1} \text { inv } v_{t}+\beta_{2} \text { tcr }+\beta_{3} p i_{t}^{\text {oecd }}+\beta_{4} p i_{t}^{\text {china }}+ \\
& \sum_{j=-k}^{j=+k} \delta_{j} \Delta i n v_{t-j}+\sum_{j=-k}^{j=+k} \phi_{j} \Delta t c r_{t-j}+\sum_{j=-k}^{j=+k} \phi_{j} \Delta p i_{t-j}^{\text {oecd }}+\sum_{j=-k}^{j=+k} \phi_{j} \Delta p i_{t}^{\text {china }}+\varepsilon_{t}
\end{aligned}
$$

En la ecuación, $p$ es el precio de los distintos productos básicos; trend, una tendencia lineal que pretende capturar mejoras tecnológicas; inv corresponde a los inventarios en bolsa para los distintos productos básicos; tcr es el tipo de cambio real multilateral de Estados Unidos; $p i^{\text {oecd }}$, la producción industrial de los países OCDE y $p^{\text {china }}$, la producción industrial de China. Todas las variables están expresadas en logaritmos. Para todos los casos, el número de rezagos incluidos $(k)$ fue igual a uno ${ }^{10}$. Luego, el modelo de corrección de errores se expresa de la siguiente manera:

$$
\begin{aligned}
\Delta \log \left(P_{t}\right)= & \gamma+\rho \varepsilon_{t-1}+\phi_{1} \Delta \log \left(I N V_{t}\right)+\phi_{2} \Delta \log \left(T C R_{t}\right)+\phi_{3} \Delta \log \left(P I_{t}^{O E C D}\right)+ \\
& +\phi_{4} \Delta \log \left(P I_{t}^{C H I N A}\right)+v_{t}
\end{aligned}
$$

El parámetro $\rho$ es el coeficiente de ajuste, dado que acompaña al error de la ecuación de cointegración rezagado en un período. El Cuadro 4 presenta los coeficientes estimados para la producción industrial de China, además del coeficiente de ajuste del modelo de corrección de errores.

Los resultados presentados confirman la importancia de incluir la producción industrial de China en los distintos modelos. Las estimaciones consideran el efecto de China sobre las distintas series individuales y agrupadas de $\operatorname{precios}^{11}$.

\footnotetext{
${ }^{10}$ Distintos órdenes de $\mathrm{k}$ fueron utilizados, de acuerdo a criterios de información y significancia estadística, no encontrándose diferencias importantes.

${ }^{11}$ Se estimaron también las ecuaciones de índices agregados de precios utilizando la definición del Commodity Research Bureau, CRB, sin registrarse cambios significativos en los resultados. También se debe mencionar que las estimaciones consideran datos mensuales desde 1995 en adelante, dada la disponibilidad de datos de actividad de China.
} 
CUADRO 4

RESULTADOS DE ESTIMACIONES PARA PRODUCCIÓN INDUSTRIAL DE CHINA

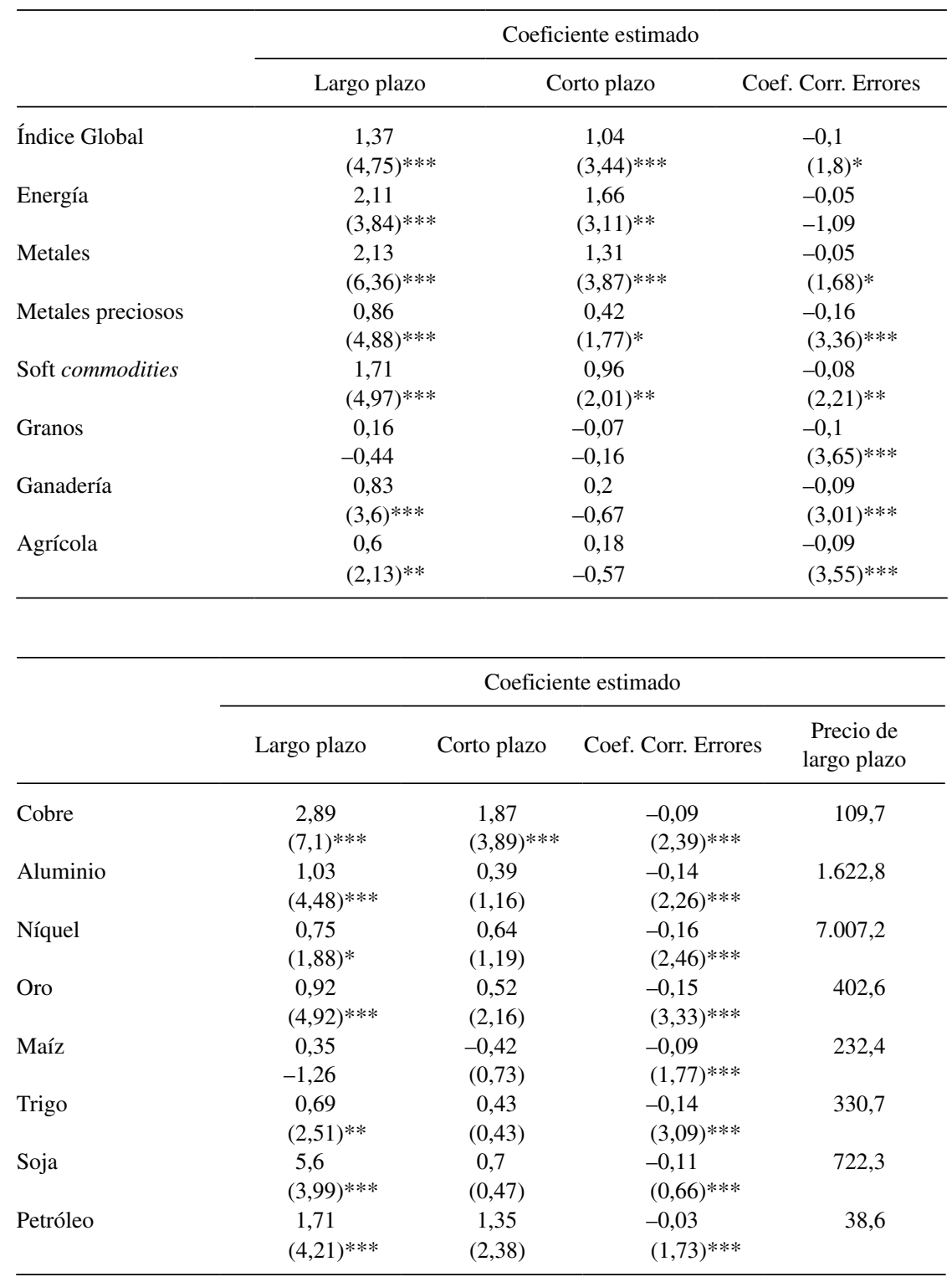

Significancia de parámetros: ***,**,* significativos al $10 \%, 5 \%$ y $1 \%$, respectivamente.

Fuente: Elaboración de los autores. 
Cabe destacar que en estos modelos, si los coeficientes de ajuste son estadísticamente distintos de cero, la variable en cuestión cambia como respuesta a shocks en las otras variables, mientras que si el parámetro es cero, la variable dependiente sólo se ve influenciada por innovaciones en los errores. Los resultados muestran que en todos los casos el coeficiente de velocidad de ajuste presenta el signo esperado (negativo), que es consistente con la posterior convergencia hacia el equilibrio en el largo plazo. En cuanto al nivel de significancia, sólo en los casos del índice de precios de energía y del precio de la soja, los coeficientes no son significativos a los niveles convencionales; esto sugiere que sólo se verían afectados por shocks en los errores. En tanto, el resto de los precios muestra coeficientes significativos, lo que favorece este enfoque de corrección de errores para la modelación de precios de commodities $^{12}$.

Observando las magnitudes de las coeficientes de ajuste, se constata la mayor velocidad de ajuste en el caso de los metales preciosos (especialmente el oro) y de los metales básicos (aluminio y níquel), con parámetros estimados en torno a -0,15; esto sugeriría preliminarmente que el efecto promedio de un shock en las variables fundamentales tardaría en desvanecer su influencia en el precio a corto plazo en un lapso no superior a los 7 meses. En tanto, la menor velocidad de ajuste para los casos del cobre, el petróleo y los productos agrícolas sugiere una mayor persistencia de estos shocks. Sin embargo, es necesario destacar que con un enfoque de equilibrio parcial, como el implícito en el modelo utilizado, no es posible dar una respuesta completa sobre la posible persistencia del shock actual que afecta a los commodities, puesto que para ello se requeriría de un enfoque más general que explicite la oferta tal como lo sugiere Pyndick (2001a y 2001b). Otros resultados interesantes se encuentran al observar los precios de largo plazo sugeridos por los modelos, una vez que se incluye la producción industrial de China. Para el caso del cobre, este sería de 109 centavos la libra, mientras para el caso del petróleo WTI sería de 38,6 dólares el barril.

Se destaca también que en la actualidad, la elasticidad del precio del cobre respecto de la producción de China se ubica en niveles cercanos a 2,9, pasando a ser significativa sólo desde el año 2000; en el caso del petróleo, la elasticidad se sitúa en torno a 1,7, reforzando su significancia desde 2003 a la fecha. En el caso de los granos y cereales, si bien el coeficiente es pequeño, de todas formas es estadísticamente significativo. Al mirar series de productos individuales, esto es especialmente cierto en el caso de la soja y el trigo. En el Gráfico 6 se presentan los coeficientes estimados de manera recursiva para cada uno de los índices agregados de precios, además del cobre y del petróleo ${ }^{13}$.

Se puede apreciar que, en la mayoría de los casos, los coeficientes de la variable de actividad de la economía china se han vuelto estables en niveles altos, incrementando significativamente su importancia en algunos casos, en los años más recientes. Nuevamente, resulta interesante constatar el hecho de que en los metales básicos (cobre, aluminio, níquel, entre otros) dicho patrón es más evidente.

\footnotetext{
12 Dado que adicionalmente las variables relevantes son integradas de primer orden (I(1)), por el Teorema de Representación de Granger, un modelo de corrección de errores necesariamente implica cointegración.

${ }^{13}$ En el Anexo A1 se encuentran los gráficos para el resto de los precios estimados.
} 


\section{GRÁFICO 6 \\ COEFICIENTES ESTIMADOS DE MANERA RECURSIVA \\ PARA LA PRODUCCIÓN INDUSTRIAL DE CHINA PARA DISTINTOS \\ COMMODITIES E INDICADORES}

Índice de Commodities de Merrill Lynch

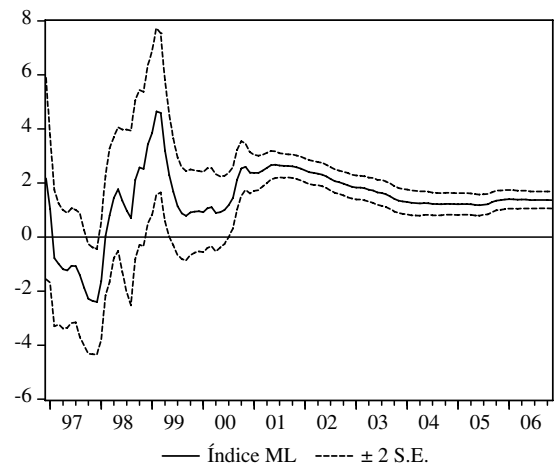

Precio del Petróleo

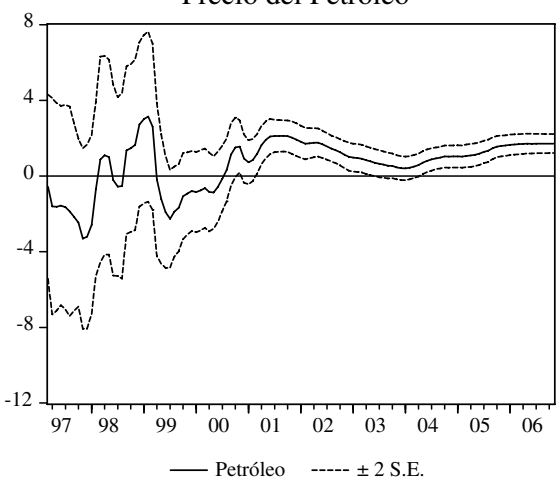

Índice Precio de Metales de Merrill Lynch

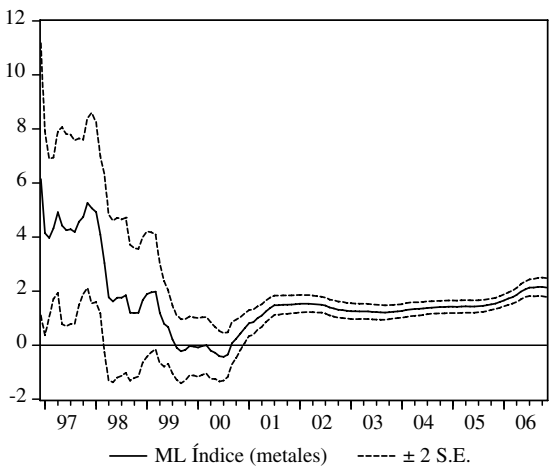

Precio del Cobre

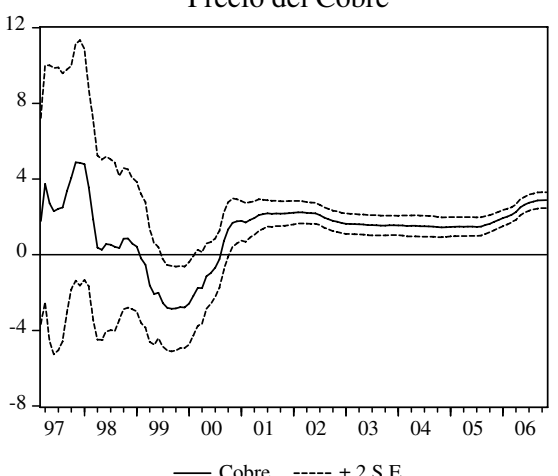

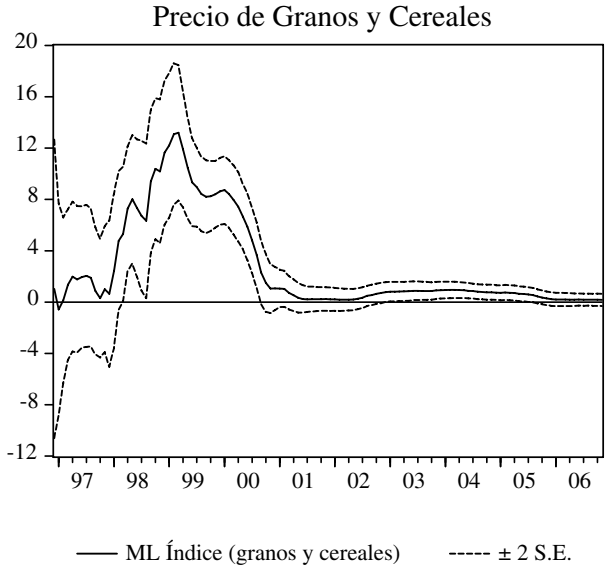

Fuente: Elaboración de los autores. 
En tanto, al comparar los errores cuadráticos medios (dentro de muestra) de un modelo genérico ( $\sin$ China) para cada una de las series de precios y/o índices de precios, se constata el mejoramiento del ajuste al incluir la producción industrial de China en el modelo. En particular, destaca que esta mejora es observada en todas las series, sin excepción alguna. En el caso del cobre, el error cuadrático medio (ECM) del modelo sin producción industrial es de $10 \%$ respecto al precio efectivo y de $22,6 \%$ al precio que subyace en el modelo genérico. En cuanto al petróleo y otros combustibles, los ECM pasan de niveles de en torno al 30\% (sin China), a $13 \%$ cuando se incluye la variable de actividad de China. En el caso de los índices de commodities, se observa que el modelo genérico para el índice de Merrill Lynch muestra errores de $17 \%$, los que disminuyen a $9 \%$ si se incluye China. Para precios de productos agrícolas también se observan mejoras en el ajuste, aunque son menos sustanciales en comparación. Por productos individuales se observa que en los precios de los metales es donde se encuentran las mejoras más relevantes en el ajuste, lo que es consistente con el hecho de que China es un importador neto de la mayoría de los metales básicos y, además, resalta como el mayor consumidor mundial en la mayoría de estos productos.

Para efectos de ilustrar más nítidamente este resultado, en el Gráfico 7 se muestran las estimaciones de los modelos considerando la inclusión y exclusión de China. Especialmente después de 2004, en el caso del índice global, se ve claramente que China explica de manera significativa la evolución de precios de commodities. Esto es relevante, sobre todo en el caso del índice de precios de metales (incluyendo al cobre).

En el caso del precio del petróleo, China comienza a jugar un rol relevante ya desde fines de los años 90, pero acentúa su importancia a partir de 2003. Se desprende que en los últimos años, en torno a un 5\% del aumento en el precio del petróleo, sería atribuible a la demanda de China analizando el período 1995-2006. Este efecto se acentuaría en los últimos años, donde cerca del 35\% del mayor precio se podría asociar al efecto de China. No obstante, cabe mencionar que los recientes acontecimientos geopolíticos que han afectado a una buena parte de los países suministradores del crudo hacen particularmente difícil modelar este mayor "premio por riesgos geopolíticos", lo que puede estar siendo capturado, en parte, por la producción industrial de China, lo que llevaría a sobreestimar el efecto de esta economía en el precio del petróleo y sus productos derivados ${ }^{14}$. En el caso del cobre, este efecto sería también sustancial donde cerca del 15\% del aumento del precio del metal se podría asociar al efecto de China ${ }^{15}$.

Un asunto de particular relevancia respecto de la evolución de precio de commodities es determinar si este boom reciente es permanente o transitorio. De acuerdo a las cifras y proyecciones sobre el crecimiento de la economía china y

\footnotetext{
14 Se realizó una estimación del riesgo geopolítico utilizando como variable proxy el VIX. Sin embargo, los resultados no cambiaron significativamente. Es probable que esta medida de riesgo no sea la óptima, sin embargo, es difícil encontrar variables que midan este riesgo.

15 Estas cifras corresponden a la diferencia porcentual sobre el precio efectivo entre la variación acumulada del precio estimado con China y la variación acumulada del precio estimado sin China.
} 


\section{GRÁFICO 7 \\ AJUSTE DE MODELOS GENÉRICOS Y \\ MODELOS QUE INCLUYEN PRODUCCIÓN INDUSTRIAL DE CHINA \\ (Expresados en logaritmos)}
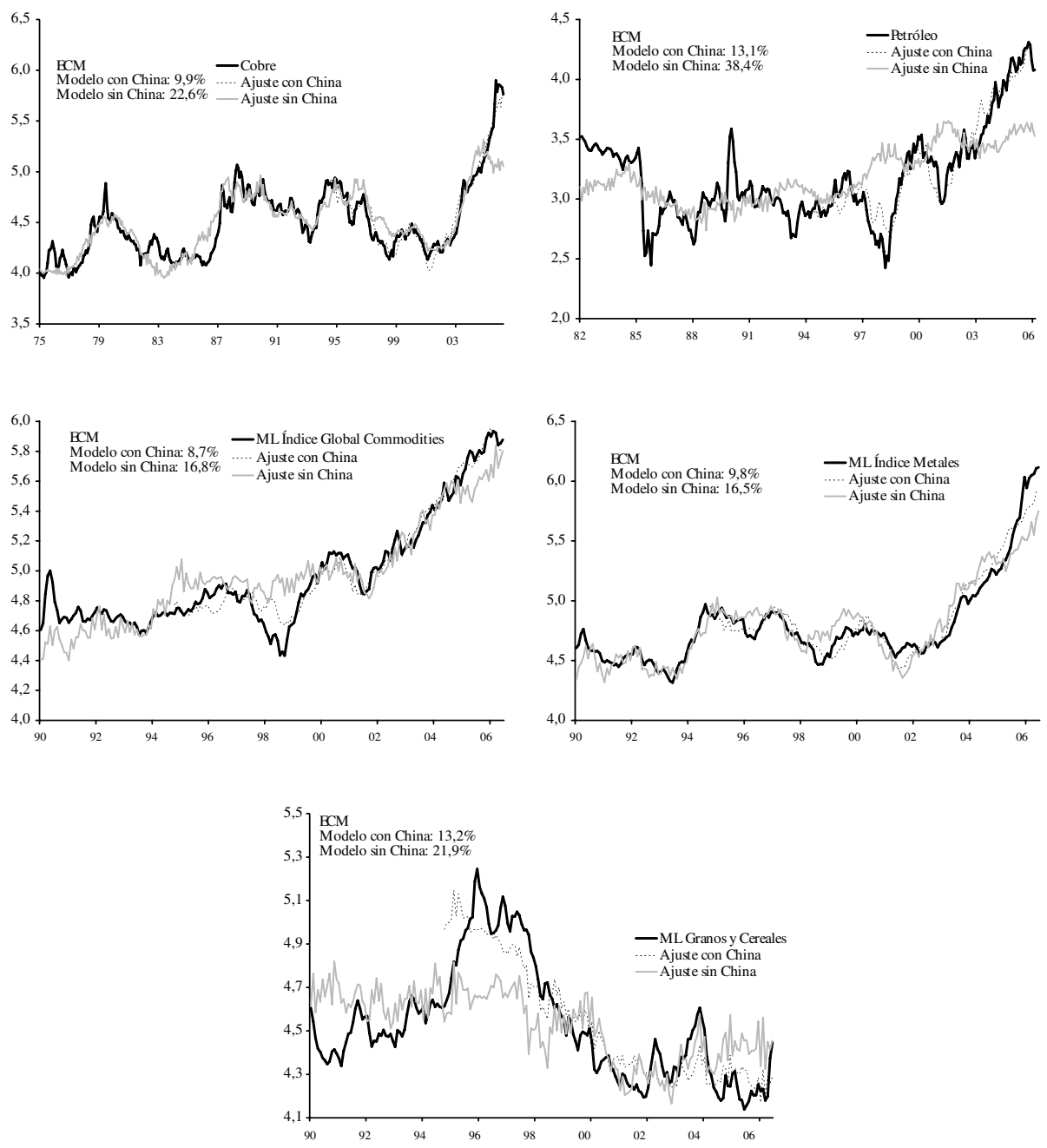

Fuente: Elaboración de los autores.

la intensidad de su producción en commodities, todo hace pensar que, mediando un lento ajuste de la oferta de los bienes, el precio de los bienes básicos debiera mantenerse sobre sus valores de largo plazo, lo que en muchos casos, como el cobre, se acentuaría dada la escasez de inventarios y limitada capacidad de la oferta para responder adecuadamente a esta mayor demanda. Esto es lo que recoge el modelo en este aspecto. Luego, este boom de commodities no depende sólo de 
que la demanda se mantenga alta, sino también de la velocidad de respuesta de la oferta ${ }^{16}$.

\section{La Economía China y América Latina}

América Latina es un continente cuya economía es bastante sensible a las condiciones externas, especialmente al crecimiento del resto de las economías, la evolución de las tasas de interés y de los spreads de deuda, además de los precios de los bienes básicos que exporta. En esta sección se busca mostrar la relación entre China, en particular, y el precio de los bienes básicos con las economías latinoamericanas.

Como consecuencia del ingreso de China a la Organización Mundial de Comercio (OMC) se ha dado un cambio gradual en la composición de la canasta exportadora desde manufacturas hacia recursos naturales; a su vez, el ciclo económico de América Latina se encuentra bastante correlacionado con China y el precio de los commodities ${ }^{17}$.

\subsection{Evolución de la canasta exportadora de América Latina}

En los Gráficos 8 y 9 observamos la evolución de la participación de China, América Latina y el Sudeste Asiático en lo referido a bienes manufacturados y recursos naturales. Como se ve, China ha aumentado su participación de manera sostenida en la exportación de bienes manufacturados, especialmente desde su ingreso a la Organización Mundial de Comercio (OMC) en 2001. Esto, sin embargo, ha sido acompañado de un leve descenso en la participación del Sudeste Asiático y América Latina (más pronunciado en el segundo), lo que da cuenta de algún desplazamiento de la producción manufacturera desde estos países emergentes. En efecto, mientras a inicios de 2000 América Latina representaba cerca del 4\% del comercio mundial de manufacturas, hoy en día se acerca a cifras en torno a 3\%. En el sudeste de Asia, luego de aumentos sostenidos durante los años 90, la proporción baja a cifras en torno a $7 \%$.

Respecto a la exportación de recursos naturales y minerales, América Latina ha aumentado de manera sostenida su participación en el comercio mundial desde

16 Se intentó calcular el precio suponiendo que los inventarios se mantienen en el promedio antes del boom, específicamente, el promedio entre 1995 y 2003. Sin embargo, el cambio en el ajuste no es significativo. Es probable que la variable inventarios no recoja toda la información respecto al comportamiento de la oferta.

17 Österholm y Zettelmeyer (2007) realizan una estimación del efecto de las condiciones externas en el crecimiento de América Latina mediante un VAR bayesiano, con supuestos a priori sobre el estado estacionario de las variables. Los resultados muestran una alta sensibilidad del ciclo, en especial al crecimiento mundial y los precios de commodities, lo que es consistente con el análisis de correlaciones presentado en este trabajo. Otras variables importantes son las tasas de interés mundiales y los spreads de deuda. 
GRÁFICO 8

EVOLUCIÓN DE PARTICIPACIÓN EN EXPORTACIONES

MANUFACTURERAS MUNDIALES

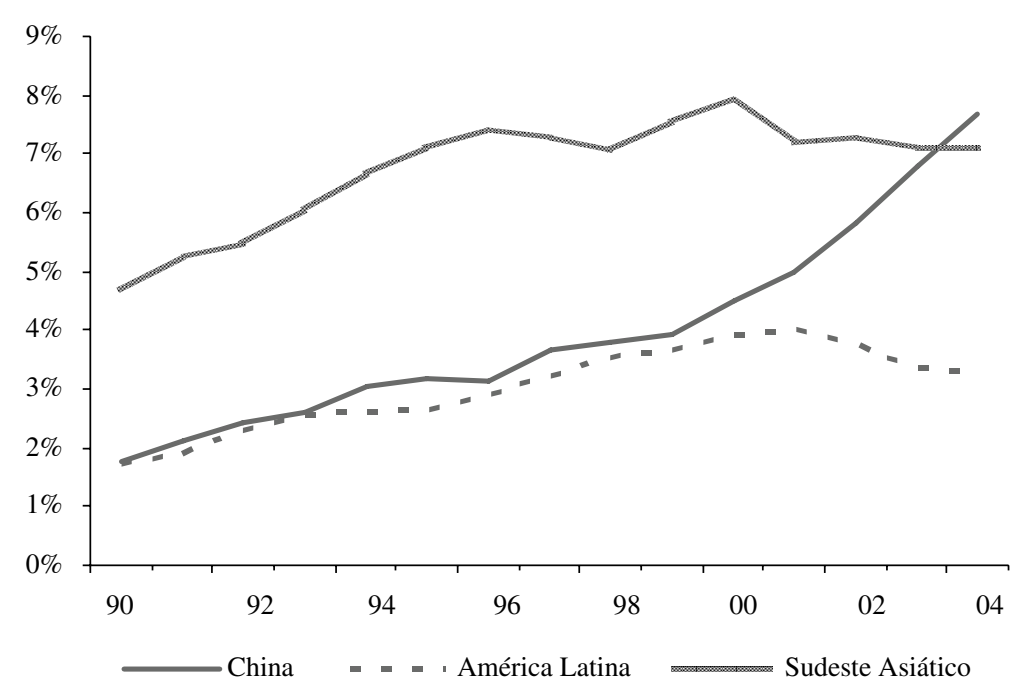

Fuente: Banco Mundial.

\section{GRÁFICO 9}

EVOLUCIÓN DE PARTICIPACIÓN EN LA PRODUCCIÓN DE RECURSOS NATURALES

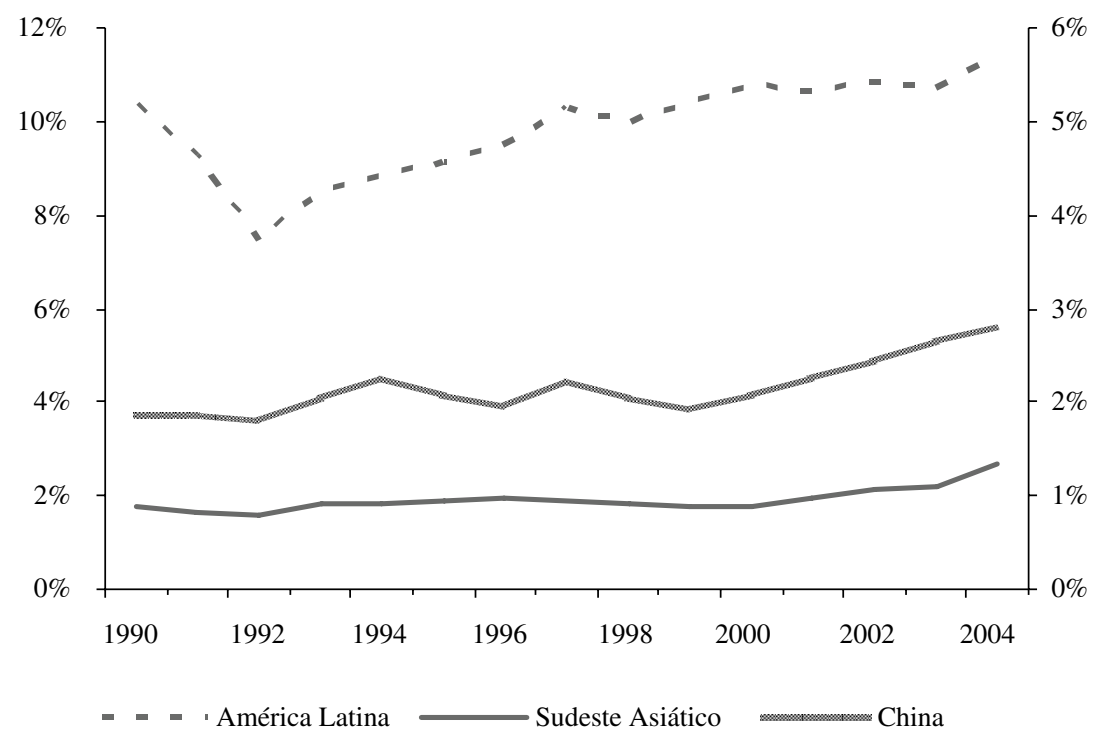

Fuente: Banco Mundial. 
los primeros años de los 90, representando hoy en día casi el 9\% del comercio mundial. De esta forma, para el caso particular de la región la irrupción de China en el comercio de manufacturas ha sido compensada por la abundancia de recursos naturales. No obstante, las historias particulares de cada país son diferentes, dependiendo de la proporción de las materias primas en su estructura económica.

De acuerdo con lo anterior, tal como lo muestra el Gráfico 10, los recursos naturales, minerales y combustibles han ido ganando espacio en la canasta exportadora latinoamericana. En conjunto representaban casi $35 \%$ de las exportaciones en 2000, mientras que en 2006 la participación de estos productos se acerca al $45 \%$ del total de envíos desde la región. Los productos manufacturados, por su parte, durante el mismo período, pasan de representar algo más de $45 \%$ de la canasta, a cifras en torno a $38 \%$.

Si observamos la situación particular de cada país, de acuerdo a cifras de 2005, se ve que, con la excepción de México y Brasil en donde transportes y maquinarias juegan un rol más importante, en el resto de las economías latinoamericanas predominan ampliamente las materias primas como principal producto de exportación. En el caso de Argentina y Colombia son los granos y cereales; en Chile y Perú, la minería y, en Venezuela, los combustibles.

GRÁFICO 10

CAMBIO EN LA CANASTA EXPORTADORA DE AMÉRICA LATINA (\%)

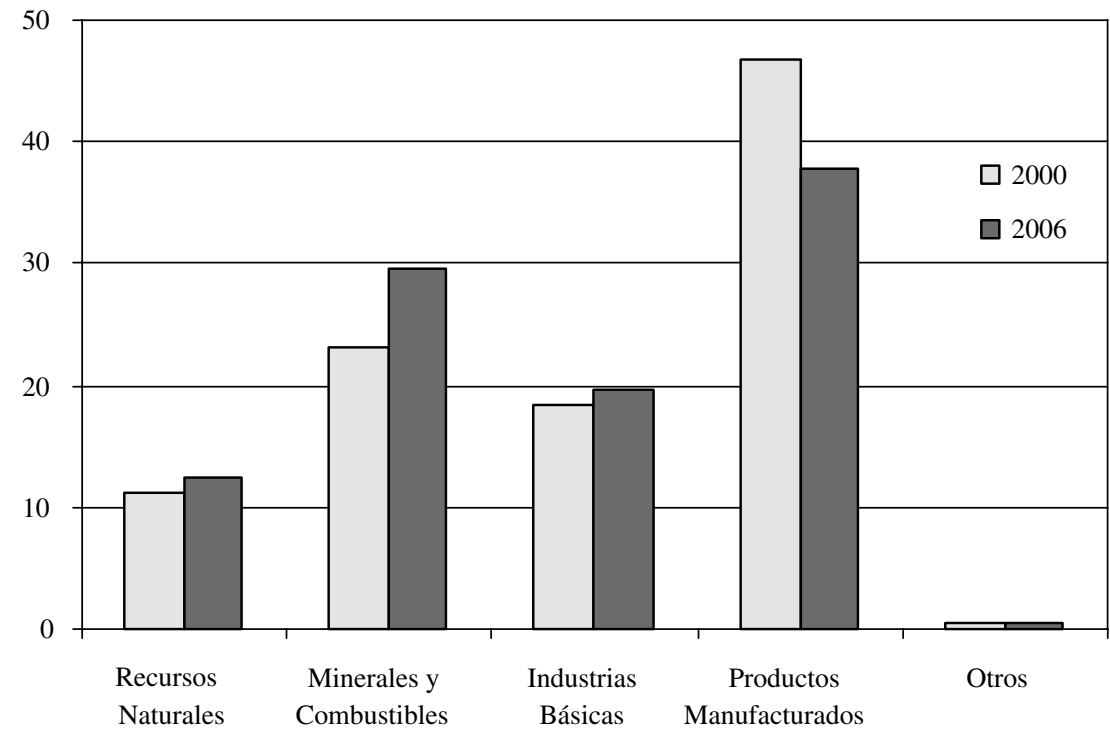

Fuente: Elaboración de los autores en base a valores de UNCTAD. 


\section{Actividad de China y el Desempeño de las Economías Latinoamericanas}

En esta sección se pretende aproximar a los efectos que China ha tenido sobre el desempeño de América Latina y sobre algunas economías específicas de la región. Como punto de partida, cabe considerar lo que nos muestra el Cuadro 5, obtenida de Blázquez-Lidoy et al. (2006), acerca del grado de competitividad de China con las economías latinoamericanas. Se entiende que mientras más alto es el grado de competitividad, menor será el efecto positivo del desarrollo económico chino o, en el peor de los casos, incluso negativo. Se destaca que, de acuerdo a este indicador que mide el grado de correspondencia entre las exportaciones de un país particular y China, México es el país que se ve más fuertemente afectado por la irrupción de los productos chinos, con un coeficiente de conformidad por sobre el 50\%. Aunque en menor grado, Brasil también debe salir a competir fuertemente con China, por lo que el desarrollo económico de este país no lo beneficiaría, en principio, de la misma manera que a otros países dentro de la región. Esto es perfectamente coherente con lo que se muestra en el Cuadro 5 analizado anteriormente.

\section{CUADRO 5 \\ COMPETITIVIDAD CON EXPORTACIONES DE CHINA 2003}

(Porcentaje)

\begin{tabular}{lccccc}
\hline & \multicolumn{3}{c}{$2002-2004$} & & 2000-2002 \\
\cline { 2 - 3 } \cline { 5 - 5 } & $\begin{array}{c}\text { Coef. de } \\
\text { especialización }\end{array}$ & $\begin{array}{c}\text { Coef. de } \\
\text { conformidad }\end{array}$ & Promedio & & Promedio \\
\hline Venezuela & 0,10 & 0,03 & 0,06 & \\
Chile & 0,14 & 0,04 & 0,09 & & 0,10 \\
Uruguay & 0,18 & 0,07 & 0,12 & & 0,11 \\
Perú & 0,19 & 0,08 & 0,14 & & 0,17 \\
Argentina & 0,20 & 0,08 & 0,14 & & 0,17 \\
Colombia & 0,25 & 0,12 & 0,18 & & 0,20 \\
Brasil & 0,30 & 0,21 & 0,26 & & 0,28 \\
México & 0,52 & 0,54 & 0,53 & & 0,57 \\
\hline
\end{tabular}

Nota: Los coeficientes de especialización y de conformidad miden el grado de similitud entre las exportaciones latinoamericanas y las chinas mediante las siguientes fórmulas:

$$
C S=1-\frac{1}{2} \sum\left|x_{a t}^{n}-x_{c t}^{n}\right| ; \quad C C=\frac{\sum x_{a t}^{n} x_{c t}^{n}}{\sqrt{\sum\left(x_{a t}^{n}\right)^{2} \sum\left(x_{c t}^{n}\right)^{2}}}
$$

El subíndice $a$ indica exportaciones de América Latina, mientras $c$ indica a China. Si estos índices son iguales a 1, entonces la canasta exportadora es idéntica y, por lo tanto, la competencia será más intensa.

Fuente: Blázquez-Lidoy, Rodríguez y Santiso (2006). 


\section{CUADRO 6 \\ COMPOSICIÓN DE LAS EXPORTACIONES DE LAS ECONOMÍAS \\ LATINOAMERICANAS \\ (\% de la canasta total para valores de 2005)}

\begin{tabular}{lrrrrrrr}
\hline & Argentina & Brasil & Chile & Colombia & México & Perú & Venezuela \\
\hline Energía y Combustibles & 16,4 & 6,1 & 2,1 & 39,2 & 14,9 & 9,3 & 88,7 \\
Minería & 8,2 & 19,4 & 58,0 & 11,3 & 6,5 & 59,5 & 6,7 \\
Granos y Cereales & 28,5 & 16,9 & 10,4 & 19,4 & 4,7 & 8,1 & 0,3 \\
Ganadería y Pesca & 18,1 & 10,2 & 9,6 & 2,2 & 0,8 & 9,2 & 0,1 \\
Industria química y forestal & 9,6 & 7,6 & 6,1 & 9,6 & 5,6 & 3,1 & 2,3 \\
Textiles y vestuario & 5,9 & 12,0 & 9,6 & 11,1 & 7,1 & 9,6 & 0,6 \\
Manufacturas & 2,0 & 1,2 & 2,4 & 0,9 & 7,2 & 0,3 & 0,0 \\
Transporte y maquinaria & 11,2 & 26,7 & 1,7 & 6,3 & 53,3 & 0,9 & 1,2 \\
\hline
\end{tabular}

Fuente: UNCTAD.

Por otra parte, debido al bajo grado de competencia entre China y las economías de Venezuela, Chile, Uruguay, Perú y Argentina, podría anticiparse que serían, en principio, los más beneficiados por el boom de China.

A continuación se analizan algunos hechos estilizados que surgen al estudiar el comovimiento (a través de correlaciones simples) de actividad y precios de commodities; de China y las economías latinoamericanas y del Sudeste Asiático, y la evolución de la composición del comercio y la producción del conjunto de economías.

La metodología para parte del análisis es análoga a la desarrollada en García, Jaramillo y Selaive (2007) para revisar el escenario internacional relevante para la economía chilena. Esta consiste en la extracción de los componentes cíclicos, a través de la aplicación del filtro de Hodrick-Prescott al logaritmo de las series temporales trimestrales y su posterior análisis de comovimiento. La aproximación al comovimiento de las series se realiza a través del examen de los coeficientes de correlación cruzada con otras variables macroeconómicas. Una serie presentará una correlación cruzada significativa con otra si el valor es superior a $0,2^{18}$.

Para examinar la fase (anticipación o retraso) de una variable respecto a otra variable macroeconómica se utilizan correlaciones dinámicas (cruzadas). De esta manera se establece que una variable antecede el ciclo por " $t$ " períodos (trimestres) si dicha correlación tiene un máximo positivo para $t<0$. En tanto, una variable se mueve con el ciclo si es un máximo para $t=0$, y se mueve con rezago respecto al ciclo si es un máximo para un $t>0$. Cabe mencionar que un análisis de correlaciones no implica necesariamente causalidad, pero sí permite distinguir cierta sincronía en los ciclos económicos durante los períodos estudiados.

\footnotetext{
18 Este valor de corte es función del tamaño muestral sobre la base de un estadístico que asume normalidad de las series. Cabe mencionar que el componente cíclico extraído por el filtro Hodrick-Prescott de las variables en logaritmo presenta media cero.
} 
El análisis considera las economías de Argentina, Brasil, Chile, Colombia, México, Perú y Venezuela en América Latina. Además, se agregan algunos ejercicios relacionados con Corea del Sur, Malasia, Filipinas, Singapur y Tailandia en el Sudeste Asiático, de modo de observar las diferencias más relevantes entre estas regiones. En cuanto a commodities, en esta sección se analizan tanto productos básicos individuales como índices agregados. ${ }^{19}$ Las series de tiempo abarcan el período comprendido entre el primer trimestre de 1997 y el tercer trimestre de 2006.

En el Gráfico 11 se ilustra el comovimiento de las economías analizadas con China. Como se puede apreciar, América Latina ha sido mucho más sensible al ciclo económico de China, el cual antecede en dos trimestres el crecimiento de América Latina. Asimismo, las exportaciones del Sudeste Asiático y América Latina se adelantan tres y dos trimestres respectivamente al crecimiento de China, lo cual podría ser explicado por el rol de suministro de partes e insumos que juegan ambos grupos de economías.

El análisis del efecto de China por país nos muestra un menor impacto sobre aquellas economías de América Latina que tienen una mayor proporción de su producto vinculada a manufacturas. En efecto, tanto en el caso de México como de Brasil se observa un coeficiente de correlación de su crecimiento del PIB con el de la economía china en torno a 0,4 ; inferior al de las economías exportadoras de commodities, como es el caso de Chile, Colombia y Venezuela, las cuales exhiben coeficientes en torno a 0,6. Los casos de Perú y Argentina son menos significativos, lo que podría deberse a que su ciclo de expansión ha comenzado de manera más tardía respecto de otras economías, dado que se han estado recuperando de un período de crisis, lo que se ha sumado a los factores externos positivos que se derivan de la expansión china. En cualquier caso, los coeficientes son significativos, dando cuenta del efecto positivo que el crecimiento de China está generando sobre del resto de las economías.

Este resultado es coherente con el análisis del impacto de China dado a conocer en FMI (2004). En este estudio se muestra que una mayor integración de China al resto del mundo tiene mayores impactos en crecimiento sobre las economías latinoamericanas distintas de México y Colombia, cuyo grado de competencia con China es más elevado. ${ }^{20}$

Los resultados obtenidos muestran también que los países exportadores de commodities adelantan el ciclo de China. Ello es coherente con el hecho de que estas economías proveen los insumos que luego se reflejan en una mayor expansión de China. En promedio, el adelanto se ubica en torno a 1 trimestre, aun cuando en el caso de algunos países el anticipo se acerca a 2 trimestres.

Por otro lado, en relación a las economías que tienen una mayor proporción de producción de manufacturas, el efecto sobre sus economías viene con rezago. Ello no es sólo válido de México y Brasil, sino también, como se aprecia en el Gráfico A5 del anexo, es aplicable a las economías del Sudeste Asiático. En el caso de estas economías, el efecto de una mayor expansión de China tendría

\footnotetext{
${ }^{19} \mathrm{Al}$ igual que en la sección anterior, también se hace el análisis con el Índice CRB, sin registrarse cambios significativos en los resultados.

${ }^{20}$ En el análisis del FMI se incluye también a Venezuela. Para mayor detalle de los resultados de este estudio, véase cuadro de Anexo A2.
} 
GRÁFICO 11

COMOVIMIENTO DE AMÉRICA LATINA Y CHINA

(1997-2005)

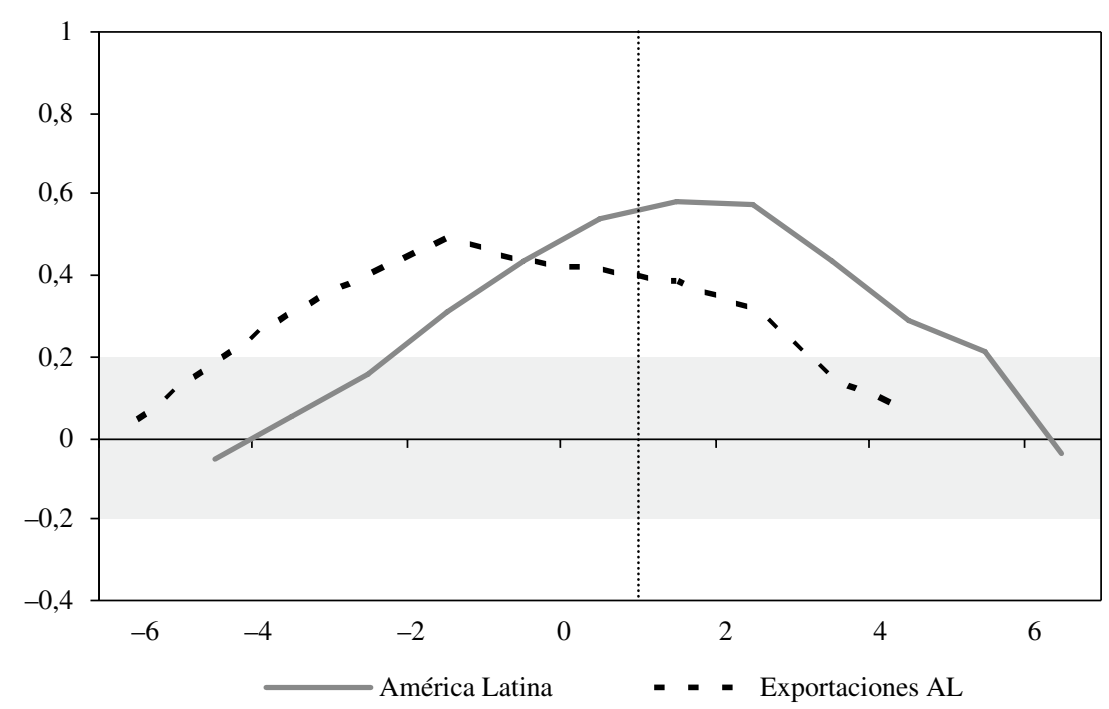

Fuente: FMI y cálculos propios.

GRÁFICO 12

COMOVIMIENTO DE SUDESTE ASIÁTICO Y CHINA

(1997-2005)

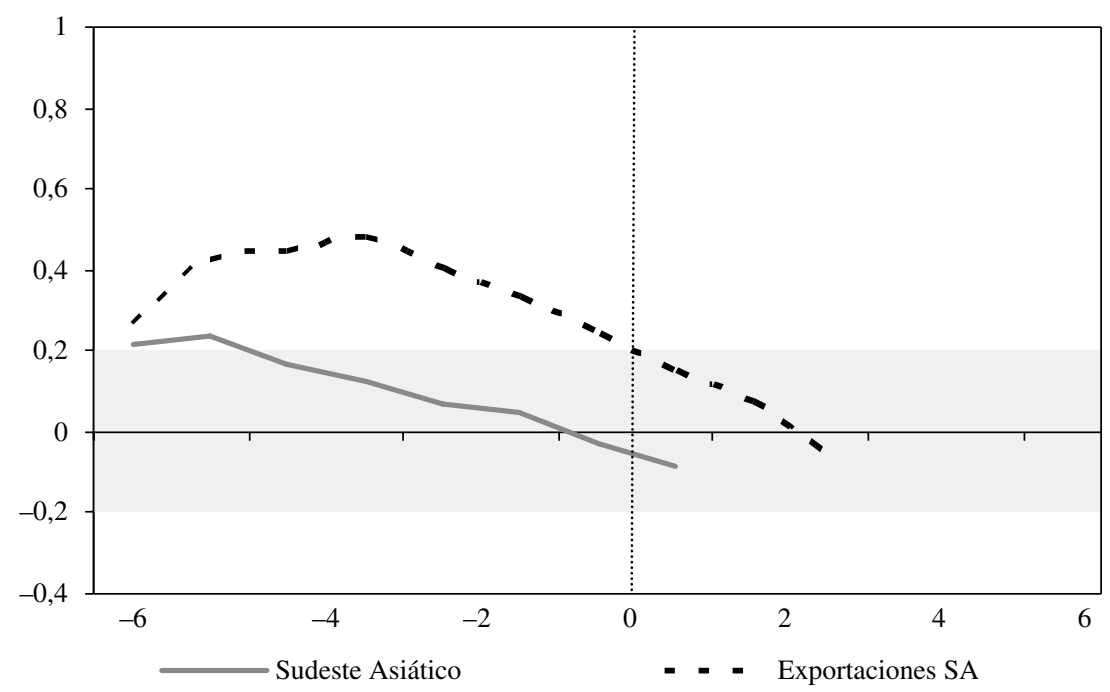

Fuente: FMI y cálculos propios. 
GRÁFICO 13

COMOVIMIENTO DE CRECIMIENTO CON CHINA

(1997-2005)
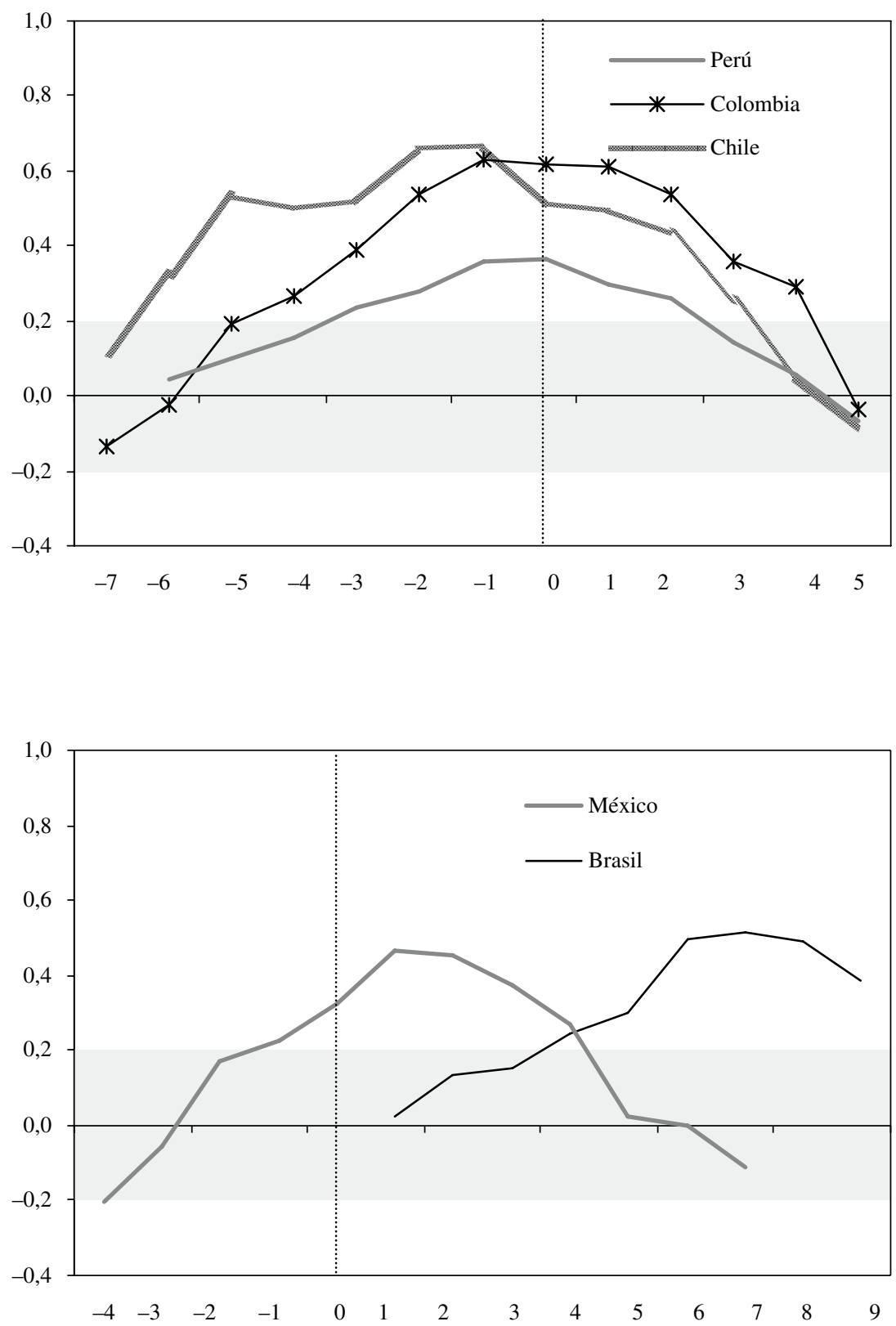


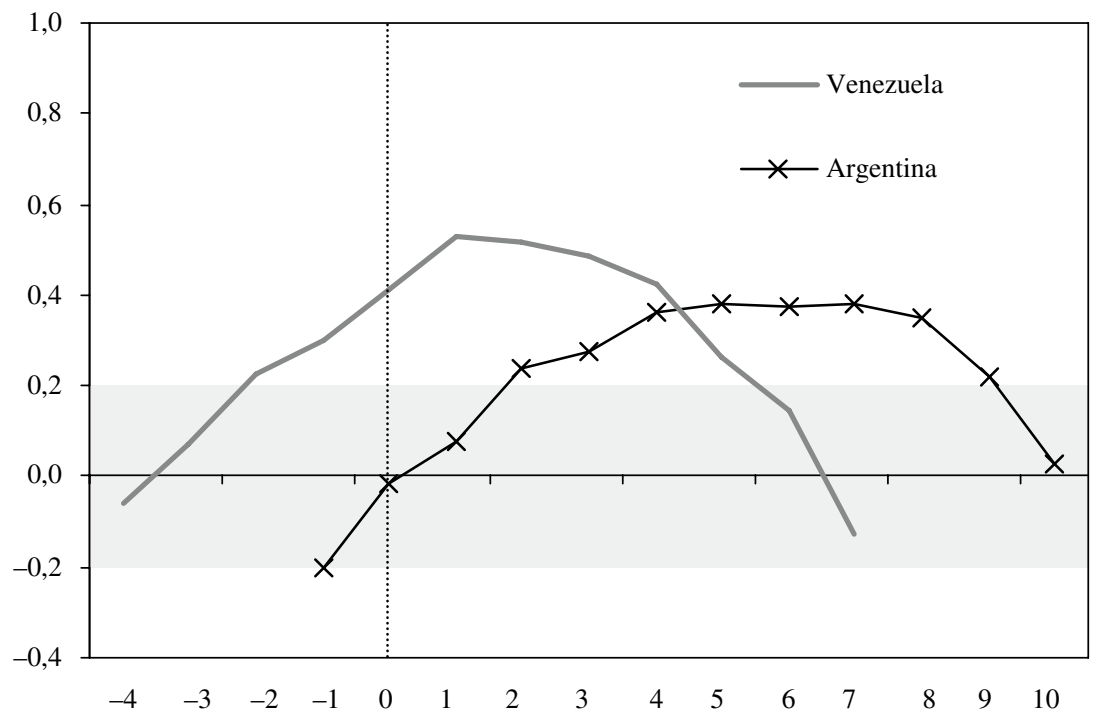

Fuente: Elaboración de los autores en base a datos del IFS del FMI y de la OECD.

un efecto rezagado, lo que se debería a una manifestación posterior del mayor consumo de bienes terminados y otros efectos indirectos, que son globales, y por lo tanto, aplicables a todas las economías, de un mayor crecimiento mundial empujado por China.

\section{Hechos Estilizados entre Precios de Commodities y Crecimiento de América Latina}

Tal como se muestra en la sección 3 de este trabajo, el crecimiento de China ha tenido un impacto significativo sobre el precio de commodities, considerando su condición actual como uno de los principales consumidores de estos productos. El Gráfico 14 nos muestra que el aumento en el precio de commodities adelanta un efecto positivo sobre el crecimiento de las economías de América Latina.

Adicionalmente, se observa que los precios de commodities adelantan en dos trimestres el crecimiento de las economías latinoamericanas, debido al efecto que se genera sobre distintos componentes de la demanda interna.

Un análisis individual para cada economía se exhibe en el Anexo 3. En el caso de Argentina, el análisis que se presenta está asociado principalmente a granos, y en el caso de Chile y Perú, a metales. Asimismo, en el caso de México y Brasil, a pesar de ser economías donde los productos manufacturados juegan un rol especialmente relevante, el petróleo y otros productos básicos también representan una fracción importante de la economía, impactando favorablemente su desempeño económico. Especialmente significativo es el efecto que el mayor precio del petróleo ha tenido sobre el crecimiento de Venezuela, considerando el alto grado de especialización de esta economía, donde cerca del $90 \%$ de sus exportaciones se vinculan a este producto y sus derivados. 


\section{GRÁFICO 14 \\ COMOVIMIENTO DE AMÉRICA LATINA Y PRECIOS DE COMMODITIES}

$(\%)$

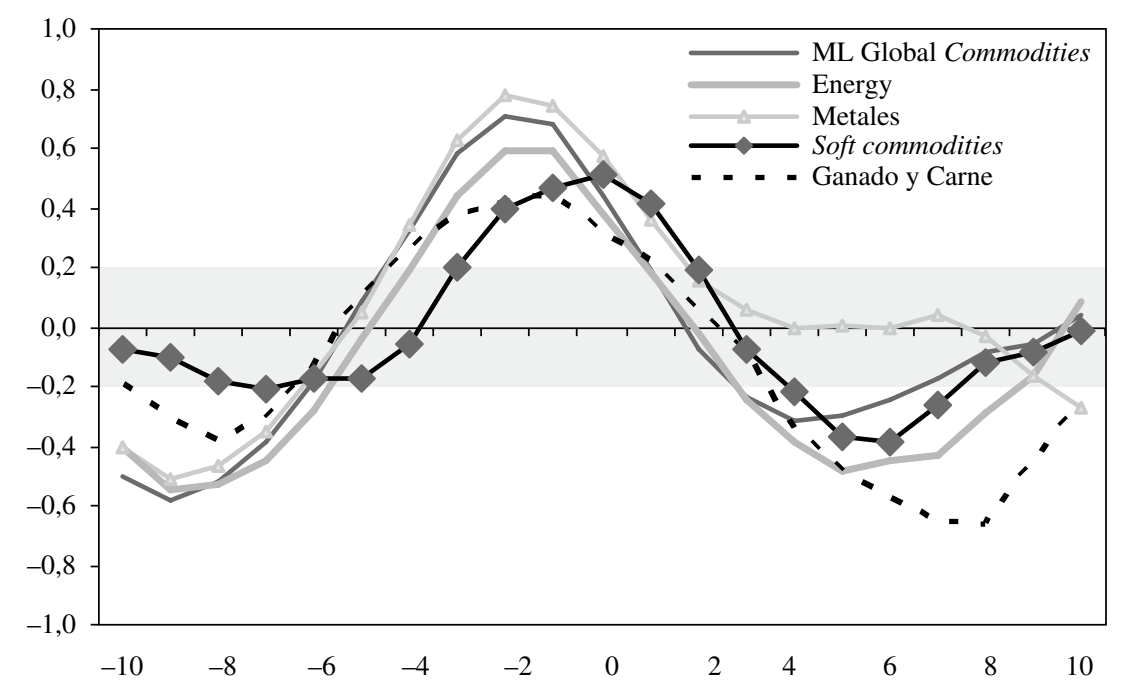

Fuente: Elaboración propia en base a Bloomberg y FMI.

\section{CONCLUSIONES}

El crecimiento de China y el significativo rol que ha adquirido como gran consumidor de materias primas ha tenido un impacto positivo sobre América Latina. Debido a su carácter más bien complementario, las economías productoras de commodities han sido las más beneficiadas. El creciente consumo de materias primas por parte de China ha tenido un impacto positivo sobre sus precios, donde este efecto ha sido estadísticamente significativo sólo a partir de 2000. Especialmente importante ha sido su papel para explicar el aumento en el precio de los metales básicos durante el período 2003-2006, particularmente en el caso del cobre, para el cual entre el 15 y $30 \%$ de las alzas de precios evidenciados en dicho período se podrían asociar a la mayor demanda de China. De igual manera, los precios de otros metales aparecen fuertemente influenciados. También importante ha sido el efecto que el consumo de combustibles por parte de China ha tenido sobre el precio del petróleo, donde se encuentra que en toda la muestra, en torno al 5\% de los cambios de precios, serían atribuibles a China, incidencia que podría llegar al $35 \%$ de los aumentos de precios durante el período 2003-2006. No obstante, el efecto en este último período se podría encontrar sobreestimado, por cuanto en las estimaciones no se incorporan variables que capturen los mayores riesgos geopolíticos que han elevado de manera importante la prima por riesgo en el mercado del petróleo y sus productos derivados. Un menor grado de relevancia tendría la actividad china sobre el precio de otros commodities, tales como cereales, café y azúcar. 
En relación a economías que aparecen más competitivas respecto de China, el impacto también ha sido positivo, pero de menor magnitud. En efecto, México y Brasil han visto favorecidos los sectores de sus economías vinculados a productos básicos. No obstante, los sectores relacionados con la producción de manufacturas en estos países han perdido participación en el comercio mundial, por lo que es importante continuar monitoreando estos efectos. Algunas economías han debido adaptarse a las necesidades de China. Esto es especialmente cierto en el caso de economías del sudeste asiático, que aparecían como fuertemente competidoras de los productos chinos, mientras que hoy día aparecen más bien como complementarias. Esto les ha permitido beneficiarse también del crecimiento chino, del que hoy día son fuertemente dependientes. En América Latina, particularmente en los países productores de commodities, la adaptación a la inserción de China en la economía mundial ha sido menos significativa o inexistente en mercados específicos de productos manufacturados. Ello ha determinado un fuerte retroceso de la región como un todo en la producción mundial de estos bienes. Hacia delante, el desafío para las economías latinoamericanas, en su mayoría intensivas en la producción de commodities, contempla administrar con responsabilidad los recursos asociados a estos mercados. Ello implica adoptar medidas tendientes a fortalecer su posición financiera, reduciendo su exposición a los ciclos y haciéndolas más resilientes a shocks externos y, al mismo tiempo, elevando la competitividad de sus economías, flexibilizando sus mercados y elevando la productividad a través de mayor inversión en educación y capacitación.

\section{REFERENCIAS}

Álvarez, R. y S. Claro (2006), “The China Phenomenon: Price, Quality or Variety?”. Banco Central de Chile, Documentos de Trabajo 411.

Bai, J. y P. Perron (1998), "Estimating and Testing Linear Models with Multiple Structural Changes". Econometrica, Vol. 66 (1): 47-78.

Blázquez-Lidoy, J.; J. Rodríguez y J. Santiso (2006), “Angel or devil? China’s trade impact on Latin American Emerging Markets". OECD Development Centre Working Paper 252.

Borensztein, E. y C. Reinhart (1994), “The Macroeconomic Determinants of Commodity Prices", IMF Working Paper 1994/9.

Dornbusch, R. (1985), "Policy and Performance Links between LDC Debtors and Industrial Nations". Brookings Papers on Economic Activity 2: 303-356.

Elliott, G., T. Rothenberg y J. Stock (1996), "Efficient Tests for an Autoregressive Unit Root", Econometrica 64: 813-836.

Engle, R. F. y C. W. Granger (1987), "Co-integration and Error Correction: Representation, Estimation, and Testing". Econometrica 55: 251-276.

Fondo Monetario Internacional (2004), "The global implications of the U.S. fiscal deficit and of China's growth”. Fondo Monetario Internacional, World Economic Outlook, abril.

Fondo Monetario Internacional (2006), “The boom in nonfuel commodity prices: can it last?". Fondo Monetario Internacional, World Economic Outlook, septiembre.

García, C., P. Jaramillo y J. Selaive (2006), "Regularidades empíricas del entorno internacional de la economía chilena". Banco Central de Chile, Revista de Economía Chilena 10 (1): 71-89. 
Gilbert, C. (1989), "The impact of exchange rates and developing country debt on commodity prices". The Economic Journal (99): 773-784.

Hansen, B. (1997), "Approximate asymptotic p-values for structural change tests". Journal of Business and Economic Statistics (1997), 15, 60-67.

Ianchovichina, E. y W. Martin (2006), "Trade Impacts of China's World Trade Organization Accession". Asian Economic Policy Review 1: 45-64.

Jaramillo, P. y J. Selaive (2006), “Actividad especulativa y precio de cobre”. Banco Central de Chile, Documentos de Trabajo 384.

Johansen, S. (1991), "Estimation and Hypothesis Testing of Cointegration Vectors in Gaussian Vector Autoregressive Models". Econometrica 59: 1551-1580.

Johansen, S. (1995), Likelihood-based Inference in Cointegrated Vector Autoregressive Models. Oxford. Oxford University Press.

Kaplinsky, R. (2006), "Revisiting the Revisited Terms of Trade: Will China Make a Difference?". World Development 34 (6): 981-995.

Krichene, N. (2005), "A Simultaneous Equations Model for World Crude Oil and Natural Gas Markets". IMF Working Paper 2005/32.

Martin, W. y V. Manole (2004), "China's Emergence as the Workshop of the World”. Stanford Center for International Development Working Paper $\mathrm{N}^{\circ} 216$.

Mayer, J. (2003), "The Fallacy of Composition: A Review of the Literature". UNCTAD Discussion Paper 166.

Mesquita, M. (2004), "Fear of China: Is there a future for manufacturing in Latin America". Banco Interamericano de Desarrollo, Documento de Trabajo 445.

Morrison T.K. and K-Y Chu (1984), "The 1981-82 Recession and Non-Oil Primary Commodity Prices”. Staff Papers. International Monetary Fund, 31: 93-140.

Österholm, P. y J. Zettelmeyer (2007) "The Effect of External Conditions on Growth in Latin America". IMF Working Paper 2007/176.

Perron, P. (1990), "Testing for a Unit Root in a Time Series with a Changing Mean". Journal of Business \& Economic Statistics, American Statistical Association, vol. 8 (2):153-62, April.

Pyndick, R. S. (2001a), "Volatility and Commodity Price Dynamics". The Journal of Futures Markets 24 (11).

Pyndick, R. S. (2001b). "The Dynamics of Commodity Spot and Futures Markets: A Primer". The Energy Journal 22 (3).

Rumbaugh, T. y N. Blancher(2004), "China: International Trade and WTO Accession". IMF Working Paper 2004/36.

Schott, P. K. (2006), "The Relative Sophistication of Chinese Exports”. NBER Working Papers 12173.

Stock, J. y M. Watson (1993), "A simple estimator of cointegrating vectors in higher order integrated systems". Econometrica 61 (4): 783-820.

US International Trade Commission (2006), "The Effects of Increasing Chinese Demand on Global Commodity Markets". Staff Research Study 28.

Watkins, C. y M. McAleer (2004), "Econometric Modeling of Non-ferrous Metal Prices". Journal of Economic Surveys 18 (5).

Yang, Y. (2003), "China's integration into the World Economy: Implications for Developing Countries". IMF Working Paper 2003/245.

Yang, T. y D.Vines (2000), “The Fallacy of Composition and the Terms of Trade of Newly Industrializing Economies". Unpublished manuscript, Oxford University. 


\section{AnEXo A1}

COEFICIENTES ESTIMADOS DE MANERA RECURSIVA PARA LA PRODUCCIÓN INDUSTRIAL DE CHINA EN LOS DISTINTOS MODELOS
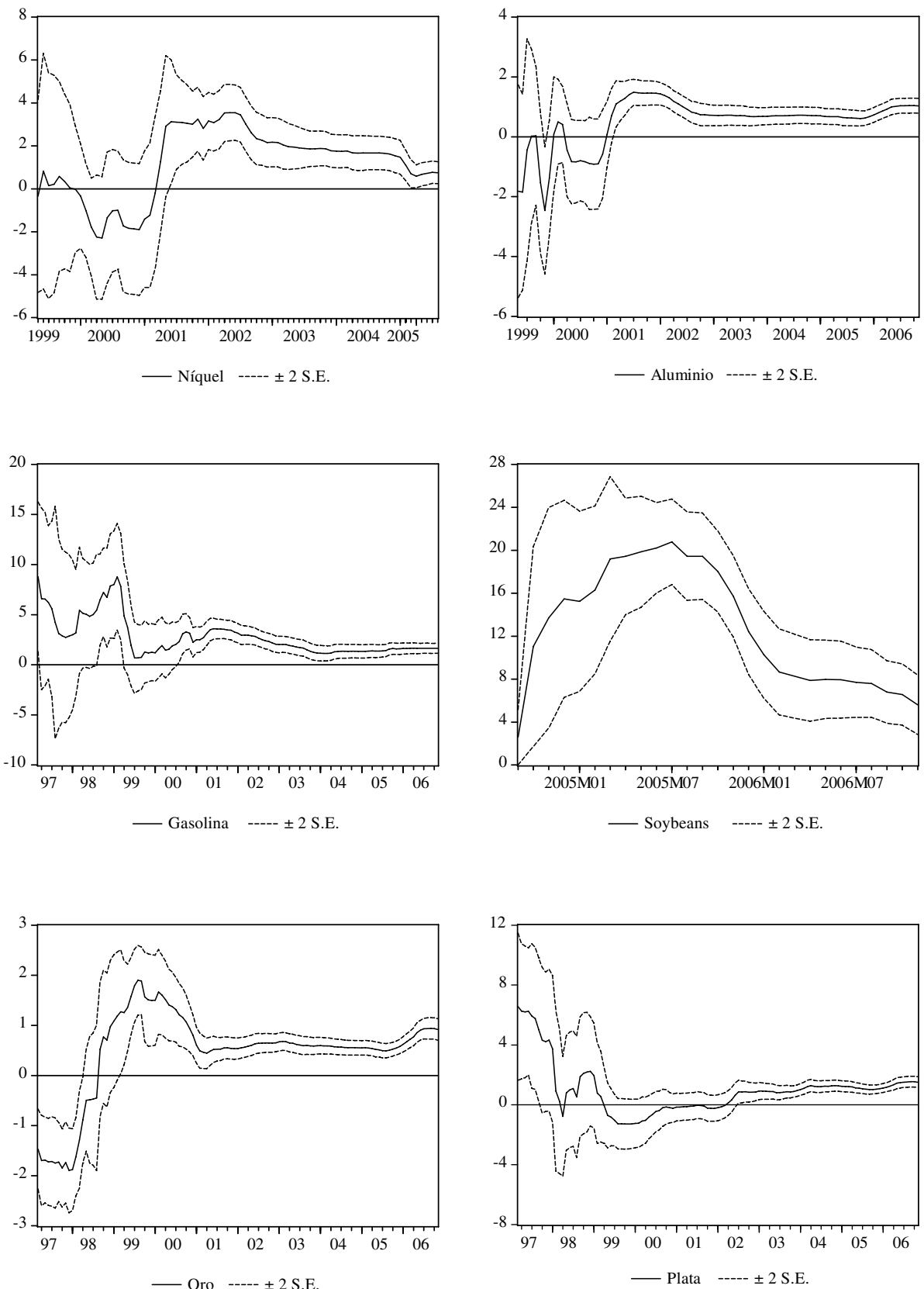

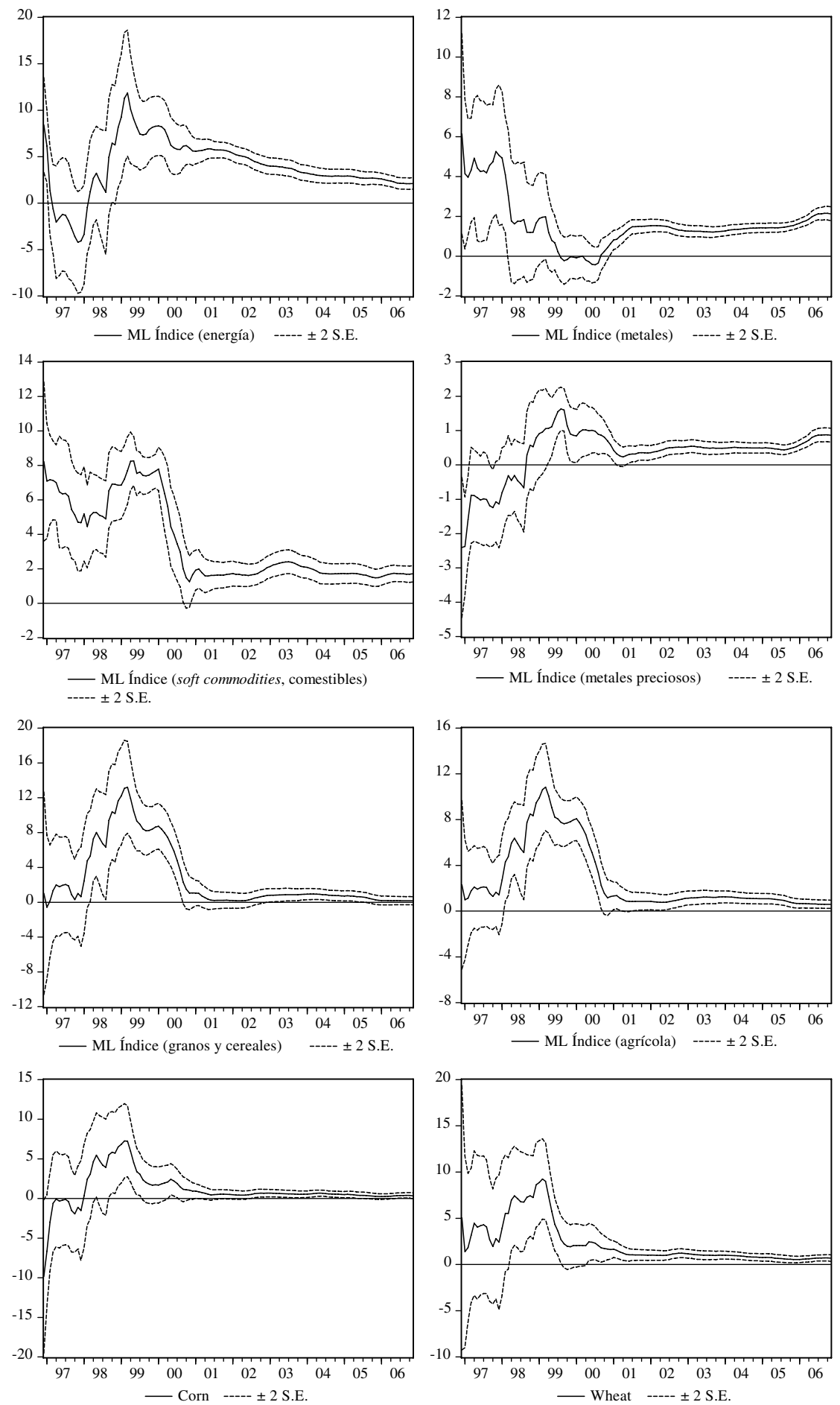

Fuente: Elaboración de los autores. 
Anexo A2

ESPECIALIZACIÓN

(Según índice de Balassa modificado)

\begin{tabular}{|c|c|c|c|c|c|c|c|}
\hline & Argentina & Brasil & Chile & Colombia & México & Perú & Venezuela \\
\hline $\begin{array}{l}\text { Productos } \\
\text { de madera }\end{array}$ & 0,44 & 2,13 & 4,53 & 0,76 & 0,27 & 0,59 & \\
\hline $\begin{array}{l}\text { Productos } \\
\text { de cuero }\end{array}$ & 2,61 & 3,68 & & 1,21 & 0,34 & & \\
\hline Químicos & 0,75 & 0,63 & 0,63 & 1,09 & 0,35 & 0,35 & 0,48 \\
\hline $\begin{array}{l}\text { Comida } \\
\text { procesada }\end{array}$ & 5,57 & 3,11 & 2,68 & 1,50 & 0,51 & 5,24 & 0,29 \\
\hline Textiles & 0,34 & 0,60 & 0,25 & 0,88 & 0,52 & 0,80 & \\
\hline Minerales & 1,42 & 0,69 & 1,33 & 2,68 & 0,67 & 1,80 & 6,69 \\
\hline $\begin{array}{l}\text { Manufacturas } \\
\text { básicas }\end{array}$ & 0,79 & 1,44 & 3,68 & 0,92 & 0,74 & 3,18 & 1,30 \\
\hline $\begin{array}{l}\text { Maquinaria } \\
\text { no electrónica }\end{array}$ & 0,30 & 0,75 & 0,08 & 0,11 & 0,75 & 0,14 & \\
\hline $\begin{array}{c}\text { Alimentos } \\
\text { frescos }\end{array}$ & 5,58 & 3,84 & 4,01 & 4,24 & 0,77 & 2,49 & 0,28 \\
\hline $\begin{array}{r}\text { Manufactura } \\
\text { miscelánea }\end{array}$ & 0,30 & 0,34 & 0,20 & 0,49 & 1,1 & 0,33 & 0,60 \\
\hline $\begin{array}{l}\text { Equipos de } \\
\text { transporte }\end{array}$ & 0,68 & 1,13 & 0,12 & 0,32 & 1,43 & & 0,90 \\
\hline $\begin{array}{l}\text { Vestuario } \\
\text { Componentes }\end{array}$ & & 0,15 & & 1,47 & 1,52 & 2,73 & \\
\hline electrónicos, & 0,10 & 0,24 & 0,05 & 0,19 & 1,56 & 0,06 & \\
\hline consumo eléctricos & & 0,38 & & & 1,96 & & \\
\hline
\end{tabular}

El índice de Balassa modificado busca ubicar la complementariedad del comercio entre dos regiones, mediante el siguiente cálculo:

$$
C S m=1-\frac{1}{2} \sum\left|x_{a t}^{n}-m_{c t}^{n}\right|
$$

La letra $x$ indica exportaciones (de América Latina) y $m$ importaciones (de China).

Fuente: Blázquez-Lidoy, Rodríguez y Santiso (2006). 


\section{Anexo A3 \\ IMPACTO COMERCIAL DE UNA INTEGRACIÓN MÁS RÁPIDA \\ DE CHINA, 2020}

\begin{tabular}{lrrrr}
\hline & Bienestar & Exportaciones & Importaciones & $\begin{array}{r}\text { Términos de } \\
\text { Intercambio }\end{array}$ \\
\hline Mundo & 5,3 & 7,4 & 7,2 & 0,0 \\
China & 126,1 & 86,6 & 85,7 & $-7,0$ \\
Economías desarrolladas & 0,1 & 2,3 & 2,7 & 0,7 \\
Nowly Industrializing & & & & \\
$\quad$ Economies (NIEs) & 0,2 & 2,2 & 2,9 & 0,5 \\
ASEAN-4 & - & 0,9 & 0,5 & $-0,1$ \\
Sureste Asiático & $-0,2$ & 0,1 & $-2,3$ & $-1,0$ \\
África subsahariana & 0,4 & 0,2 & $-0,8$ & 1,4 \\
México, Colombia & & & & 0,3 \\
$\quad$ y Venezuela & 0,1 & $-0,7$ & $-1,2$ & \\
Otras economías & & & & 0,9 \\
$\quad$ emergentes del & & & & \\
$\quad$ Hemisferio Occidental & 0,2 & 2,5 & 2,8 & 0,4 \\
Medio Oriente y África & & & & \\
$\quad$ del Norte & 0,7 & $-0,8$ & 0,4 & 0,6 \\
Resto del Mundo & 0,1 & 1,3 & & \\
\hline
\end{tabular}

Fuente: WEO abril de 2004.

Notas: El impacto se mide como desviación porcentual de los valores bajo un escenario de integración más lenta. Bienestar es definido como la variación equivalente en relación al PIB. Se utilizan precios FOB para exportaciones y CIF para importaciones. La discrepancia en exportaciones e importaciones refleja costos de transporte. 


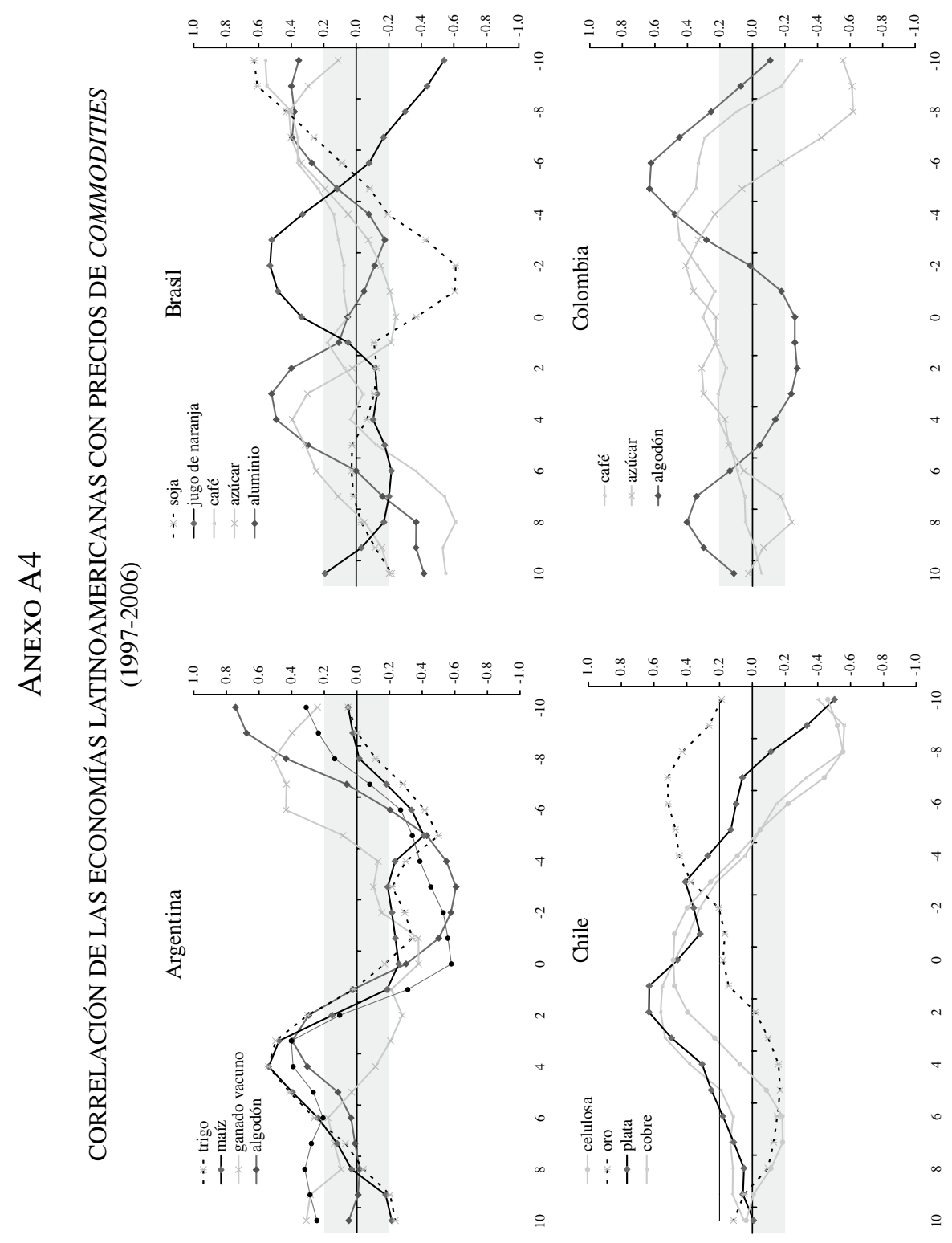




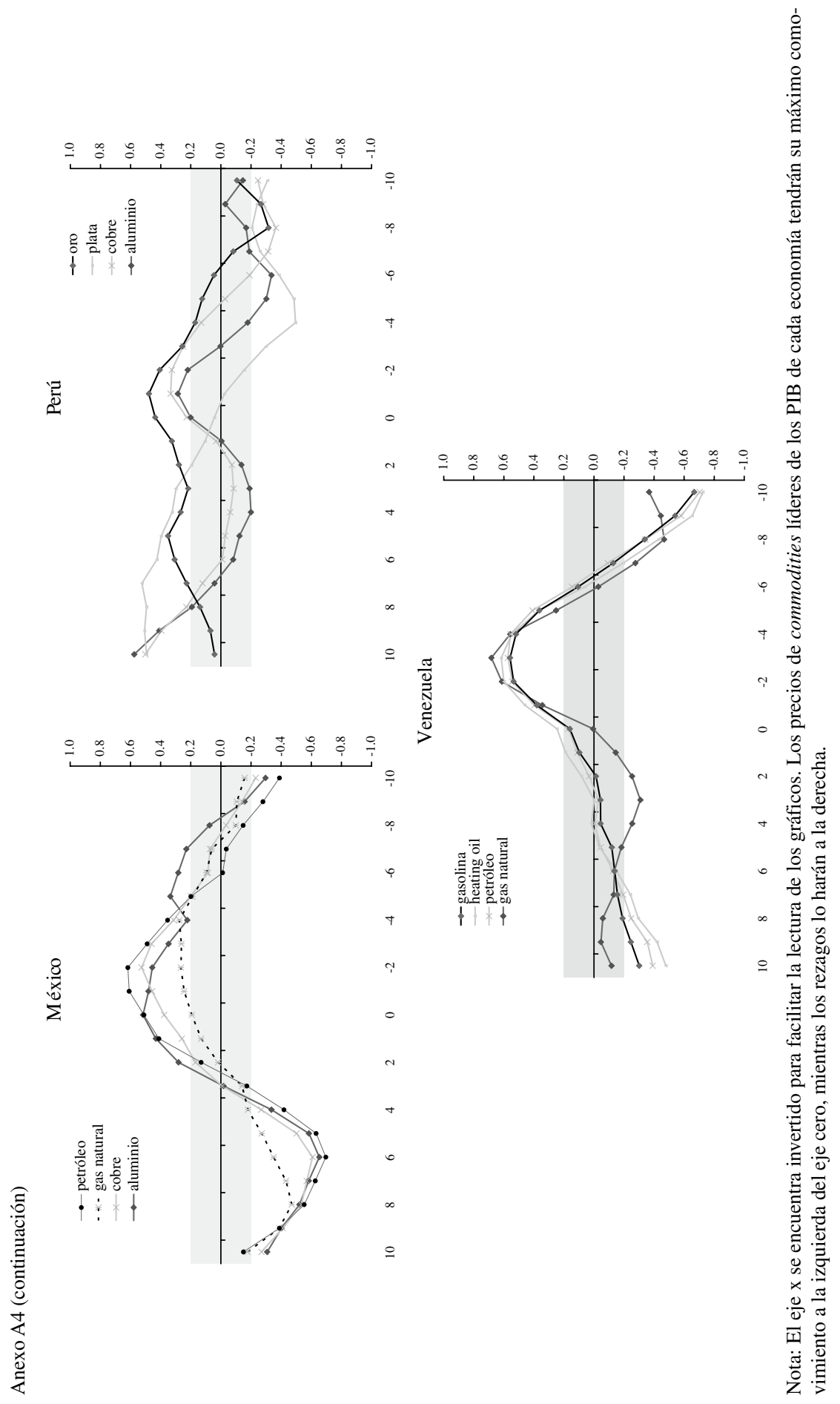


Anexo A5

COMOVIMIENTO DE ECONOMÍAS ASIÁTICAS CON CHINA

(1997-2006)

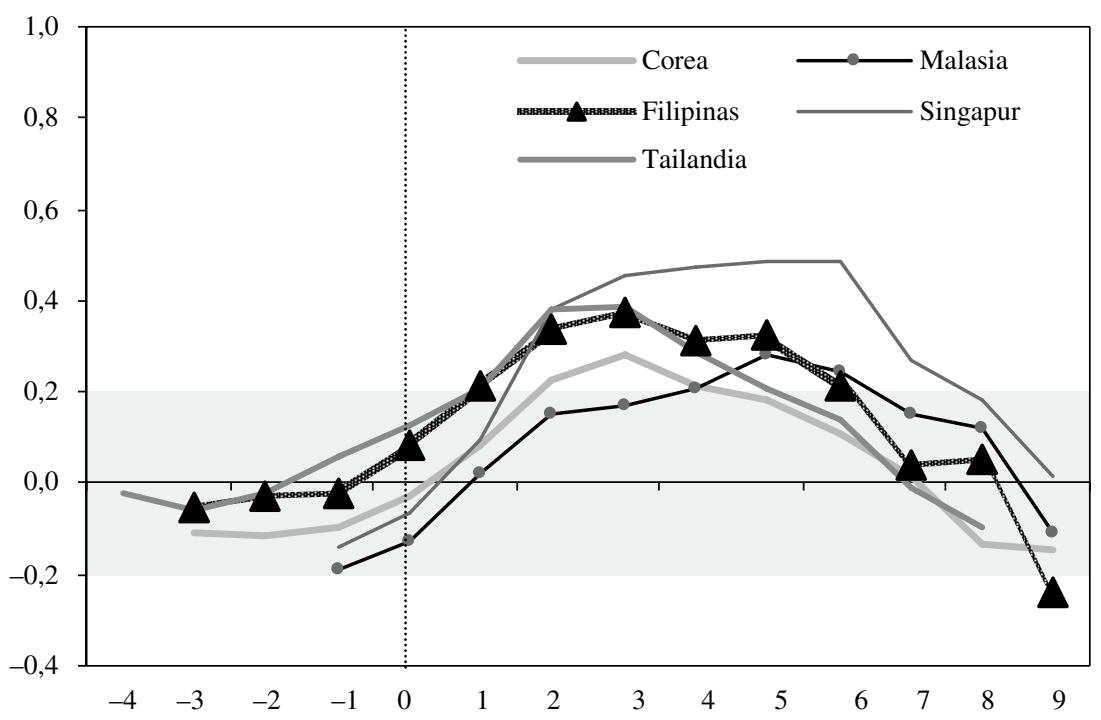

Fuente: Elaboración de los autores. 